\title{
ELECCIÓN DE SEPULTURA Y ESPACIO FUNERARIO: SANTA MARÍA LA REAL DE NÁJERA (SIGLOS XI-XV)*
}

\author{
POR \\ MARgarita CANTERA Montenegro ${ }^{1}$ \\ Universidad Complutense de Madrid
}

\begin{abstract}
RESUMEN
La elección de sepultura refleja la religiosidad medieval y la búsqueda de oraciones, así como un medio de afianzar la memoria del linaje, ya sea real o nobiliario. Santa María de Nájera fue panteón de los reyes de Navarra hasta la incorporación de la región a Castilla en 1076 y la posterior entrega del templo a la Orden de Cluny; perdida en ese momento la función de panteón regio, fueron las familias nobles de la zona, especialmente los Haro, las que eligieron el claustro de este monasterio como lugar de entierro, dando lugar al conocido como Claustro de los Caballeros. Asimismo, personas de toda condición social y los familiares del monasterio tuvieron derecho a sepultarse en otras alas del claustro, a excepción del primer Duque de Nájera, que lo hizo en el interior de la iglesia.
\end{abstract}

PALABRAS CLAVE: entierros en monasterios; elección de sepultura; panteón real de Navarra; panteón nobiliario; familiares del monasterio.

\section{CHOICE OF BURIAL AND FUNERAL SPACE: SANTA MARÍA LA REAL DE NÁJERA (XI-XV CENTURIES)}

\begin{abstract}
The choice of a tomb reflects the religious feelings and the search for prayers, as well as a mean of guaranteeing the memory of the lineage, whatever it is of royal or noble origin. Santa María de Nájera was the pantheon of the kings of Navarra until the annexation of this territory to Castile in 1076 and the subsequent delivery of the church to the Order of Cluny; lost in that time the function of royal pantheon, noble families, specially the Haro, chose the cloister of the monastery as a burial place, since then known as the Knight's Cloister. In the same way, people from every social condition and familiares of the monastery were entitled to be buried in other wings of the cloister, with the exception of the first Duke of Nájera, who lays inside the church.
\end{abstract}

KEY WORDS: burials in monasteries; choice of burial; royal pantheon of Navarra; noble pantheon; family monastery.

COMO CITAR ESTE ARTículo / CiTATION: Cantera Montenegro. M. 2017. «Elección de Sepultura y espacio funerario: Santa María la Real de Nájera (siglos XI-XV)» Hispania Sacra 69, 140: 455-469. doi: 10.3989/hs.2017.028

Recibido/Received 05-05-2015

Aceptado/Accepted 14-05-2015

\section{INTRODUCCIÓN}

El monasterio de Santa María la Real de Nájera tiene su origen en la fundación realizada por el rey García III de Navarra, conocido como el de Nájera, el 12 de diciembre de 1052 para acoger el obispado de Calahorra, hasta que pudiera reconquistar la antigua sede. El monarca tuvo un

* Este trabajo se ha realizado en el marco del Proyecto de Investigación: Identidades, contactos, afinidades: la espiritualidad en la Península Ibérica (siglos XII-XV), HAR2013-45199-R, dirigido por la Dra. D. Isabel Beceiro Pita.

1 mcantera@ucm.es / ORCID iD: http://orcid.org/0000-0001$6686-6286$ especial interés en potenciar este templo como capilla regia y sede episcopal, como pone de manifiesto la rica dotación fundacional ${ }^{2}$; pero añadió, además, la función de panteón real, con toda la carga simbólica que conllevaba este acto

2 El estudio del monasterio najerense, analizando de forma detallada estos primeros años de su existencia, en Cantera Montenegro 1987, y de forma más breve, pero ampliando el espacio cronológico a toda la Edad Media, Cantera Montenegro 2001. En esta importancia de la fundación de Santa María de Nájera insiste Fortún Pérez de Ciriza 2005: 232-233; asimismo señala que la obra artística del templo najerense «reflejaba la función de un centro religioso como escenario de la magnificencia de una monarquía» (ibídem: 211). 
como medio de mantener el recuerdo de la dinastía ${ }^{3}$ y hacer visible la imagen mental y del ideario de la monarquía; se trata, por tanto, de un lugar de referencia para sus súbditos ${ }^{4}$, demostrando por medio de él de forma visible la prolongación del poder regio. ${ }^{5}$

Junto al indudable afecto religioso a su nueva fundación, en la elección por García III del templo najerense para su entierro hubo también una clara intencionalidad política, pues era una forma de asegurar el dominio del territorio riojano. Pero en 1076, tras el asesinato de Sancho IV el de Peñalén, La Rioja fue incorporada a la Corona castellana, lo que supuso una transformación importante en el templo najerense, pues tres años después de ese hecho el rey Alfonso VI lo entregaba a la Orden de Cluny con un doble objetivo: favorecer su proyecto de reforma monástica; y, al tiempo, obtener el respaldo político de esta Orden, tan vinculada a su familia y persona, para asegurar la unión a Castilla de la ciudad y su región.

Por otra parte, este cambio de dinastía también supuso que el templo najerense dejó de ser panteón regio, aunque los descendientes más directos de García III fueron enterrados allí. No perdió, pese a ello, su importancia como cementerio, pues el prestigio de haber sido panteón real movió a otras personas, especialmente a algunas familias de la nobleza, a solicitar que sus cuerpos descansaran en él. En primer lugar fue la poderosa familia Haro que, teniendo buena parte de su patrimonio en la región riojana, quiso consolidar su posición con su protección al monasterio najerense y la fijación en él de su enterramiento; hecho nunca casual, sino buscado explícitamente como medio de proyectar su memoria y prestigio después de la muerte y asegurar la pervivencia del linaje y apellido. ${ }^{6}$ Algo semejante ocurrió siglos después con el primer Duque de Nájera, Pedro de Mendoza, que también trataba de afianzar su señorío en la ciudad con el patrocinio sobre el cenobio, inmiscuyéndose en los conflictos internos de la comunidad con motivo de la reforma, lo que planteó a la larga, como luego veremos, problemas para su entierro.

Y cuando se fue apagando el fervor de la familia Haro hacia el monasterio, otros linajes nobiliarios lo escogieron como lugar de entierro. Y, al mismo tiempo, se fue abriendo a personas de toda condición social.

Hasta el siglo XII estaba expresamente prohibido el entierro en el interior de los templos, y sólo de forma excepcional se incumplió esta norma; por este motivo los enterramientos privilegiados se establecieron generalmente en el pórtico de las iglesias, como ocurría en los monasterios románicos, pues aun estando a las puertas del templo era un lugar de comunicación directa con el espacio consagrado.? Ya a partir del siglo XII empezó a introducirse la costumbre

\footnotetext{
3 Fortún Pérez de Ciriza (dir.) 1991: 272.

4 Martínez de Aguirre Aldaz 2003.

5 Mitre Fernández 2002: 39. Mattoso 1995: 401-402. Boto Varela 2012: 536. Guiance 1998: 314, señala ejemplos de diversos factores que movieron a los reyes a escoger un determinado lugar de sepultura: de carácter "histórico», familiares, ambiciones personales, devociones propias o razones políticas.

6 Ver sobre el particular el trabajo de Ortego Rico 2008: 277-278 y 307.

7 Sobre este aspecto hay que recordar el detallado estudio Bango Torviso 1992. También es importante el ya citado trabajo de Martínez de Aguirre Aldaz 2003.
}

de establecer estos enterramientos dentro de las iglesias, utilizando habitualmente el arcosolio, arco abierto en el muro del templo, que permitía realizar una jerarquización de las personas a enterrar $y$, al tiempo, no estorbaba a los fieles en las ceremonias religiosas. ${ }^{8}$

También se utilizaron como espacios funerarios las galerías y jardines de los claustros y los muros exteriores de las iglesias, especialmente para el entierro de nobles; por ello, como ocurre en Santa María de Nájera, se les suele llamar "Claustro de los Caballeros». ${ }^{9}$

\section{IMPORTANCIA DE LA ELECCIÓN DE SEPULTURA}

La elección de sepultura solía incluirse en los testamentos a continuación de la encomendación del alma, lo que indicaba que se consideraba un acto de especial trascendencia, pues con ello se anhelaba asegurar la oración por la salvación eterna del difunto, gracias en buena medida a las limosnas y donaciones efectuadas a favor del templo receptor. También suponía crear unos lazos de mediación recíproca entre los vivos y los difuntos, un cauce por el cual estos últimos quedaban inscritos en la sociedad de los vivos, ya fuese a nivel familiar, parroquial, ya en el seno de una comunidad religiosa ${ }^{10}$; y este último caso era especialmente importante, pues garantizaba la oración continuada por parte de la institución que acogía el cuerpo, fundamental para alcanzar la salvación eterna. ${ }^{11}$ Por ello, en las donaciones realizadas a los centros eclesiásticos y monásticos se insistía siempre, como justificante del acto, en la solicitud de oraciones por los difuntos de la familia y, por parte de los reyes, en la petición de oración por la paz y estabilidad de sus propios reinados. ${ }^{12}$

De este modo, en la elección del lugar de sepultura podían influir factores como la devoción a una iglesia o monasterio concretos, o a una Orden religiosa, la veneración a un santo junto a cuyas reliquias o sepulcro se quería descansar, el ser la iglesia parroquial del testador o la cercanía de otros familiares difuntos para mantener los lazos de familiaridad incluso más allá de la muerte. ${ }^{13}$

En otras ocasiones podía primar un factor de carácter social, por el deseo de enterrarse en una iglesia con prestigio. En este sentido cabe destacar la importancia de las catedrales, como fue la de Nájera durante sus primeros años, así como de la Orden de Cluny, a la que perteneció

\footnotetext{
8 Bango Torviso 1992: 113-116. Martínez de Aguirre Aldaz 2003: 141. Pavón y García de la Borbolla 2008: 221-237; tratan de los problemas surgidos entre los obispos y las Órdenes mendicantes por los derechos económicos que conllevaba la elección de sepultura.

9 Martínez de Aguirre Aldaz 2003: 140.

10 En ello insisten Pavón y García de la Borbolla 2008: 213-214, al señalar que «determinar el lugar de inhumación se presentaba como otro recurso de intercesión más».

11 Ibídem: $216-217$ y 219. Señalan las autoras, refiriéndose al caso del cenobio de Leire, que «el monasterio se convierte en el espacio terrenal por excelencia desde donde acceder directamente al Cielo».

12 Son muy numerosas las donaciones realizadas a favor de Santa María de Nájera que incluyen como móvil concreto de esos actos la oración por el propio donante y/o sus familiares; pero no las analizo aquí al limitar el estudio a aquellos casos en que se constata de forma directa o indirecta la concesión de sepultura en el recinto monástico.

13 Cantera Montenegro 1986: 119.
} 
Santa María a partir de 1079, pues esta Orden había desarrollado desde sus inicios una especial devoción a la conmemoración de los bienhechores difuntos ${ }^{14}$, entre los que destacaron los monarcas de la dinastía pamplonesa, tanto los navarros como los castellanos.

La Iglesia trató de armonizar la libertad de elección de sepultura con el respeto a los legítimos derechos económicos de las parroquias, motivo por el cual el papa León III estableció que en caso de producirse el entierro en una iglesia distinta a la parroquial, ésta debía recibir una parte de los bienes que se dejaban a la elegida; es la porción canónica o parroquial, cuyo haber variaba según las zonas. ${ }^{15}$ Sin embargo, a pesar de esta regulación, surgieron frecuentes conflictos por el deseo de muchos fieles de enterrarse en monasterios o conventos de mendicantes y no querer satisfacer la cuota obligatoria. ${ }^{16}$

\section{SANTA MARÍA dE NÁJERA COMO PANTEÓN DE LOS REYES DE} NAVARRA $^{17}$

Santa María de Nájera fue panteón de la familia real navarra en el siglo $\mathrm{xI}$, siendo el lugar destinado a ello un espacio excavado en la roca a occidente del templo románico, comunicado con la misma, pero no con el exterior, y que se hallaba junto a la cueva donde, según la tradición, el rey García encontró la imagen de la Virgen, origen de la fundación. ${ }^{18}$ De esta forma lo describió el cronista fray Antonio de Yepes: «así se trazó la de Santa María, de tal manera que viniese la cueva a ser a los pies de la iglesia y allí se pudiesen enterrar los reyes». ${ }^{19}$

Aquí fueron enterrados los monarcas García III y su hijo Sancho IV con sus respectivas mujeres; pero después perdió su función de panteón de los reyes navarros, pues incluso tras restaurarse la dinastía en 1134 los monarcas fueron enterrados en su mayoría en la catedral de Pamplona.

Recuperó temporalmente su papel de panteón, por expresa voluntad del rey viudo, al recibir el cuerpo de la reina doña Blanca, hija de García IV, mujer de Sancho III de Castilla y madre del heredero Alfonso VIII; pero en ello influyó, más que el deseo de depositar el cuerpo de su

14 La importancia concedida por la Orden de Cluny a la oración por los difuntos, que se plasma en el establecimiento de la fiesta de los fieles difuntos el día 2 de noviembre, el día siguiente a la festividad de Todos los Santos, ha sido puesta de manifiesto de forma especial por lognaPrat 1996-1998 y 2002. En esos trabajos, el autor destaca el papel que el abad san Odilón tuvo en ello y la relevancia del cambio realizado en Cluny respecto a la época carolingia, al pasar de la recomendación global de los vivos y muertos a la conmemoración personal de los fallecidos inscritos en las necrologías, de la memoria colectiva a la individual (en concreto, en logna-Prat 2002: 540).

Por ello, Cluny se convirtió también en un espacio funerario de primer orden, con la existencia de dos cementerios, uno para los monjes y otro para los laicos, estando incluso el primero abierto a los laicos bienhechores del cenobio; con ello aumentaron las donaciones ad sepulturam. Un estudio arqueológico de los enterramientos en el monasterio es el realizado por Baud 1999.

15 Orlandis 1950: 40 y 47

16 Algunos ejemplos para el ámbito riojano en Cantera Montenegro 1986: 119 y $146-147$

17 Este punto ha sido estudiado con detenimiento en Cantera Montenegro 2014

18 Dectot 2006: 355.

19 Yepes 1960: 94, vol. III. mujer en el panteón de sus antecesores navarros, el resaltar y consolidar la pertenencia a Castilla de esta ciudad y territorio. ${ }^{20}$

En la actualidad, este panteón está cerrado por una gran reja de hierro; pero en su momento inicial seguramente estaría más separado de la iglesia, formando un cuerpo independiente que permitía hablar de la "Capilla de los Reyes» como parte diferenciada de la misma. Parece probable que hasta el siglo XVI no hubiese sepulturas monumentales, como ratifica fray Prudencio de Sandoval, al decir que D. Estefanía fue sepultada junto a su marido «bien a lo llano se hizo la sepultura en un arca de piedra, como se usaban en aquellos tiempos; después se labraron otras, y pusieron con bultos levantados, y los de los Reyes de rodillas orando hacia el altar mayor». ${ }^{21}$

Pero junto a este panteón situado en el coro bajo, los enterramientos de personajes reales se encuentran en otros tres sitios: en la capilla de la Cruz, situada en la iglesia cerca del anterior panteón; en la propia cueva; y en la capilla de la Vera Cruz o de la reina D. a Mencía, en el claustro. ${ }^{22}$

Desde principios del siglo XIV abundan las noticias sobre el estado ruinoso de la iglesia najerense, a cuyos pies se encontraba el panteón regio, hasta que en el siglo xV se iniciaron algunas obras destinadas a rehacerla o, quizás mejor, a hacerla de nuevo, durante el priorazgo de Pedro Martínez de Santa Coloma (1422-1453). ${ }^{23}$ Bajo el abad fray Rodrigo de Gadea (1556-1559) se empezó la obra del panteón, especificando fray Antonio de Yepes que «por los años de 1556» dicho abad había "puesto orden en los sepulcros de los reyes... en su capilla real ${ }^{24}$, aunque el proyecto tardaría bastantes años en ser completado.

El confusionismo de la historiografía del siglo XVII, las leyendas borradas o casi borradas de algunos epitafios, la tradición mal interpretada y posiblemente un deseo de enriquecer el panteón son elementos combinados que han dado lugar a diversas listas de enterrados en este recinto. ${ }^{25}$

Es indudable el entierro de los reyes fundadores, García III de Nájera y su mujer la reina Estefanía, pues junto a las

20 Dectot 2009: 188-189. En el mismo sentido se manifiesta el traductor de Dectot 2006: 356, nota 2.

21 Sandoval 1614: fol. 62 vo

22 La descripción de estos espacios, realizada con gran detallismo técnico y precisión en Moya Valgañón (dir.) 1986.

${ }^{23}$ Archivo Histórico Nacional, Clero, leg. 2963, Libro 2º de censos. Las obras se continuaron en la segunda mitad del siglo XV, terminando la capilla mayor y otras capillas de la iglesia, el coro de los órganos y presbiterio, la sillería del coro alto, la capilla de Santa Catalina y el claustro de los Caballeros, la sacristía y los dormitorios de los monjes cuyos cimientos se habían podrido por las abundantes lluvias.

24 Yepes 1960: 123, vol. III.

25 Yepes 1960: 92-99, vol. III. Fray Antonio de Yepes se detuvo en realizar la descripción de 26 sepulcros de la que llama Capilla de los Reyes y en la que se integra tanto el panteón real propiamente dicho como la ahora conocida como Capilla de los Infantes o de Santa Cruz. Aun siendo fray Antonio de Yepes un hombre cuidadoso a la hora de contrastar los datos que proporciona y de haber vivido cuatro años en el monasterio najerense, de forma que pudo conocer con detalle tanto el edificio en sí como la documentación allí conservada en su tiempo, en este caso no fue especialmente crítico y dio credibilidad a las leyendas de los epitafios de las tumbas y a la tradición, sin poner en duda algunos de los datos aportados. También hay que tener en cuenta que Yepes no pudo contemplar las tumbas originales, sino la obra del siglo XVI, cuando se rehizo y reordenó totalmente el panteón. 
referencias cronísticas cercanas en el tiempo, su hija doña Mayor, al hacer una donación en 1077 afirma hacerlo por amor a sus padres ibídem quiescientium. ${ }^{26}$ También parece que están enterrados en Santa María de Nájera, al menos así lo afirma Yepes, los ocho hijos de estos monarcas: el heredero Sancho IV el de Peñalén, Ramiro, Fernando, Raimundo, Urraca, Ermesinda, Jimena y Mayor; y otros dos hijos que murieron siendo niños, Jimeno y Gonzalo. ${ }^{27}$ El entierro de Sancho IV el de Peñalén en este panteón de Nájera es muy probable, siguiendo la tradición recogida por Yepes, aunque las crónicas guardan silencio total sobre el lugar donde fue enterrado. ${ }^{28}$

En el panteón de reyes se encuentra la sepultura del infante Ramiro García, hijo de García III, cuya tumba tiene el escudo real de Navarra. Por ser infante no le correspondería haber sido sepultado allí, sino en la Capilla de la Cruz o de los Infantes. Pero en este hecho hay que ver una clara reivindicación de la legitimidad dinástica, ya que al morir su hermano Sancho IV él fue considerado por algunos nobles el legítimo sucesor del trono.

Por su parte, la capilla de la Cruz o de los Infantes es un claro testimonio de cómo la iglesia se fundó para capilla real, manteniéndose en ella el culto en memoria de los fundadores $^{29}$, tal como lo afirma fray Antonio de Yepes al señalar la continuidad que en su tiempo seguía produciéndose en los oficios religiosos ofrecidos por los reyes y sus familiares enterrados en este panteón: «Por muchos siglos, no sólo los monjes eran capellanes de los cuerpos reales que allí están enterrados, pero a mano derecha había una capilla que llaman de la Cruz, donde hacían sus oficios clérigos que servían también de capellanes de los reyes; yo, cuando vivía en Nájera, los alcancé que hacían este ministerio». ${ }^{30}$

En esta capilla se encuentran catorce arcas sepulcrales de piedra que parecen corresponder a los infantes Mayor, Jimena, Fernando, Jimeno, Urraca, Ermesinda y Raimundo, hijos de los fundadores; Ramón y Sancho, hijos de Sancho IV; los hijos de García IV el Restaurador Sancho y Alonso Ramírez, señor de Castroviejo, y la mujer de éste, D. a Sancha de Zúñiga; D. a Ágelo Muñoz, biznieta de los fundadores e hija de Munio Muñoz, que hizo una donación al monasterio

26 Cantera Montenegro 1987: doc. 21. En 1081 su hermano Ramiro realizó una donación al ya monasterio cluniacense, afirmando que lo hacía por remedio anime mee atque requie parentum meorum Garsie regis vel matris mee Stephanie regine, pero no alude de forma directa a su entierro. Ibídem, doc. 23.

27 Yepes 1960: 92-98, vol. III. Reglero de la Fuente 2008: 264, nota 117 , señala que esta lista resulta problemática, pues no coincide totalmente con otros datos de la descendencia del rey García III o de su lugar de enterramiento.

28 Yepes 1960: 94-95, vol. III. Pavón y García de la Borbolla 2008: 75 y 157; las autoras señalan que las fuentes sólo han trasmitido el acto del fratricidio, pero no se sabe el destino de sus restos mortales, ni siquiera si llegó a recibir la cobertura funeraria acorde con sus prerrogativas y medios económicos personales. En el mismo sentido se expresa Dectot 2009: 157 y nota 65.

29 Moya Valgañón 1989: 70.

30 Yepes 1960: 93, vol. III. También se deduce esto del texto del plano que del monasterio hizo en 1596 Francisco de Odriozola en una de las fases de obras que se realizaron en el mismo a lo largo del siglo XVI (entre ellas, una posible ampliación de la citada capilla de la Cruz); al referirse a esta capilla dice "a donde los cappelanes della an estado del año de 1052 en que los instituyó el rey don Garçía, fundador deste Real monasterio» (Archivo Histórico Nacional, Mapas, planos y dibujos de Clero, $\mathrm{n}$ ㅇ 63). por las almas de sus padres, marido e hijos ${ }^{31}$; y Mayor Ordóñez, hija de los condes de Nájera.

Presidiendo la capilla se encuentra la tapa del sepulcro de doña Blanca de Navarra, hija del rey García IV el Restaurador y casada con el futuro rey de Castilla Sancho III el Deseado, fallecida poco después de dar a luz a su único hijo, Alfonso VIII. Su sepultura estaba en el panteón regio, a los pies de la iglesia, pero al remodelar el conjunto en el siglo XVI se quiso guardar, con gran acierto, esta tapa monumental románica. ${ }^{32}$

También en la cueva estaría antiguamente parte del panteón; y en la actualidad se conservan allí dos sepulcros modernos; uno de ellos tiene una inscripción con el nombre Don Álvaro. ${ }^{33}$ En un principio habría al menos cuatro sepulcros, como se recoge en el plano del monasterio que realizó en 1596 el maestro cantero Fernando Odriozola ${ }^{34}$, pues señala en la cueva cuatro huecos con la leyenda infante. Parece tratarse del infante Gonzalo García, hijo de los fundadores, de los infantes Sancha Garcés y Álvaro, hijos de García IV, y de Toda López de Haro, hija de Lope Îñiguez, VII señor de Vizcaya. ${ }^{35}$

La memoria de los reyes y de sus familiares enterrados en este panteón se mantuvo a través del monumento en sí. Pero también a través de la oración que desde el primer momento se elevó a Dios por los allí acogidos. Así lo afirmaba D. - Toda Pérez, viuda de Diego López de Haro, quien al donar al priorato najerense en 1215 varias posesiones, solicitaba que se celebrase por las almas de su marido y de sus padres un aniversario, como se decía anualmente por las de los reyes. ${ }^{36} \mathrm{Y}$ fray Antonio de Yepes se encargó de recordar que se mantenía esta memoria en el siglo XVII.

Pero también los reyes conservaban el recuerdo del panteón allí establecido. Así, Fernando IV en 1312 al conceder al monasterio citado un privilegio lo justificaba «porque sé que en la eglesia de Santa María de Nagara ay muchas reliquias et es muy devota, et yacen y muchos reyes et reynas, et infantes et infantas, et los de Vizcaya et los de Agoncillo et otros muchos buenos ommes et dueñas». ${ }^{37}$

31 Cantera Montenegro 1987: doc. 29, año 1113.

32 Moya Valgañón 1986: 52-53. Este sarcófago ha sido minuciosamente estudiado y analizado desde el punto de vista de la Historia del Arte por los siguientes autores, añadiendo progresivamente interesantes aportaciones sobre el mismo: Íñiguez Almech 1968: 200-203; Álvarez-Coca González 1978; Martínez de Aguirre Aldaz 2003: 146-147 y 158; Valdez del Álamo 2006: 805-806; y, de forma especial por el detaIlismo del estudio, Valdez del Álamo 2000: 43-79; y, de forma más breve, Valdez del Álamo 2001.

En un primer momento el sarcófago se colocó en un arcosolio en la capilla de la Cruz, mutilando para ello parcialmente su cabecera; y allí permaneció hasta que a principios del siglo xx se decidió apartarlo de la pared. En su emplazamiento en el arcosolio lo fotografió Arco 1954.

33 Moya Valgañón 1986: 54.

34 Archivo Histórico Nacional, Mapas, planos y dibujos de Clero, n으 63.

35 Así lo afirmaba Sandoval 1614: 56. PP. Franciscanos. s.a. Santa María la Real de Nájera. Guía del visitante: sin paginar, llama Teresa a esta última.

36 Cantera Montenegro 1987: doc. 114. Sobre la intercesión de los monjes de Cluny por los reyes de Castilla y León véase Reglero de la Fuente 2008: 192-198; el autor señala cómo la oración no se hacía sólo en el propio monasterio de Cluny, sino también en sus prioratos españoles (especial atención en Santa María Nájera en pp. 197-198); y Reglero de la Fuente 2014: 36-38. Madrid:

37 Cantera Montenegro 1987: doc. 228. 
Planta de la iglesia de Santa María la Real de Nágera en la forma en que está 1596. Plano, simplificado, de Francisco Odraizola (Archivo Histórico Nacional, Clero, Mapas y planos, no 63.

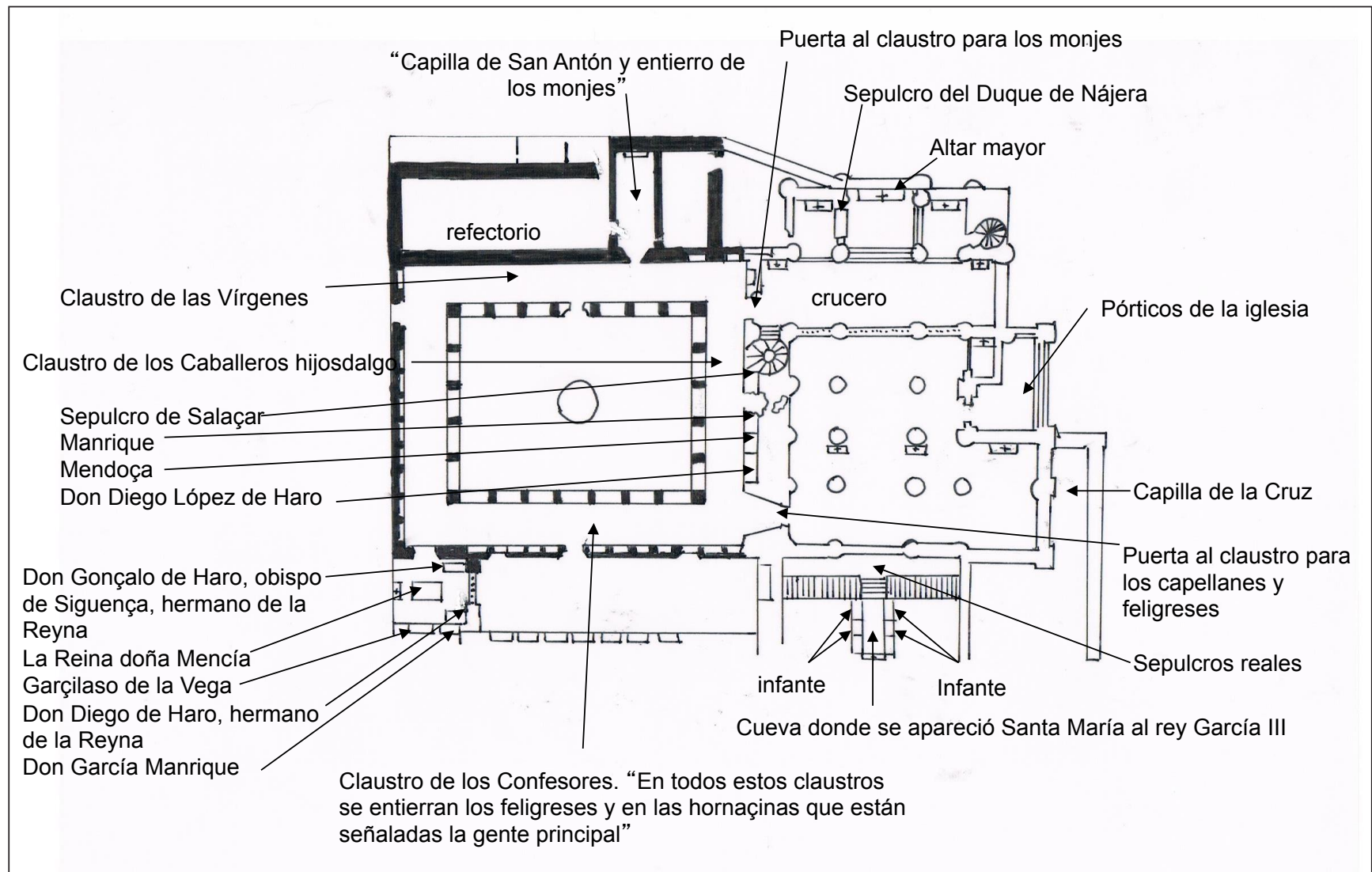

\section{ENTERRAMIENTOS EN EL CLAUSTRO}

Además del panteón regio situado a los pies de la iglesia y en la Capilla de la Cruz, el claustro najerense acabó conformándose como lugar de entierro, verdadero cementerio. Ello supuso, como en otros casos, la adaptación de la arquitectura a esta función, añadida a la propia de articulación de espacios de la comunidad ${ }^{38}$, de forma que con el tiempo casi desaparecerían del claustro algunas de las actividades comunitarias del clero, sus reuniones se ubicarían fuera de su entorno y se concentrarían sus oficinas en una de las pandas o galerías. ${ }^{39}$ Por otra parte, también proporcionó una fuente de ingresos económicos, derivados tanto de los derechos de enterramiento como de la celebración de aniversarios.

La localización de los enterramientos en el claustro aseguraba la participación en los beneficios espirituales de la comunidad y de las ceremonias religiosas habituales en sus galerías, como eran las procesiones ${ }^{40}$; además, por ser lugar de paso habitual de los monjes, gozarían del recuerdo y oración de los mismos. Desde el principio hubo una verdadera jerarquización de los espacios, siendo el lugar preferente la pared contigua a la iglesia y, más aún, la puerta de los monjes. ${ }^{41}$

38 Sobre este tema Español 2003: 11-29; García Flores 2005: 199229; Martínez de Aguirre 2003: 138-141; Carrero Santamaría 2006.

39 Carrero Santamaría 2006: 32

40 Español 2003: 23-25.

41 García Flores 2005: 221; Martínez de Aguirre 2003: 140.
La fórmula arquitectónica más habitual de adaptar el claustro para cementerio era realizar una serie de retranqueamientos en el muro, formando arcosolios monumentales. Y precisamente el claustro de Santa María de Nájera es mencionado por el prof. Carrero Santamaría como ejemplo de ello, presentando "en sus muros perimetrales una galería de sepulcros en arcosolio, trasdosados por una cornisa en la que apoyan los nervios del abovedamiento. Recibe el nombre de Claustro de los Caballeros por su dedicación a panteón de familias nobles». ${ }^{42}$ Yepes $^{43}$ lo describe como «paño de los Caballeros, que está arrimado a la pared y se extiende entre aquellas dos puertas que salen a ella», refiriéndose a las puertas de la iglesia hacia el claustro, la situada a los pies de la misma, junto a la capilla de los reyes, y la que se abre hacia el crucero, la de los monjes.

El claustro de Santa María de Nájera es, como lo describe el prof. Moya Valgañón ${ }^{44}$, «un cuadrángulo irregular de nueve tramos en los lados largos, este (de los Mártires) y oeste (de los Confesores), y siete en los cortos, norte (de las Vírgenes) y sur (de los Caballeros o Apóstoles) con dos plantas... Los lados perimetrales [del claustro bajo] se ordenan para sepulturas

42 Carrero Santamaría 2006: 34 y 42. Las obras del claustro, realizadas entre 1517 y 1528, se comenzaron con el abad fray Juan de Llanos (1517-1521) y se terminaron en el de fray Diego de Valmaseda (15211528), como recoge Ruiz Maldonado 1996: 94

43 Yepes 1960: III, 99.

44 Moya Valgañón 1986: 56 
con dos arcosolios por tramo, unos rebajados y otros de medio punto, con inscripciones, muchas perdidas o en mal estado, en los frentes de las tapas, y escudos en los de las cajas".

En el caso de Santa María de Nájera sólo la panda o galería este, el conocido como claustro de los mártires, no tenía prevista una función cementerial y a él se abrían el refectorio y la capilla de San Antón, lugar de entierro de los monjes y que mandó construir el abad Pablo Martínez de Uruñuela. ${ }^{45}$

Aunque en el claustro se recogieron principalmente los cuerpos de personas de posición social relevante, y así fue sobre todo en los primeros momentos, se convirtió en lugar accesible para todo tipo de personas por medio de donaciones, especialmente por la fórmula conocida como traditio corporis et animae, mediante la cual los donantes se convertían en miembros de la comunidad. ${ }^{46}$

Sin embargo, había una clara jerarquización de los espacios, incluso en la galería o claustro de los Caballeros, en el cual se señalaron muy pronto tres zonas o grados de importancia para los entierros, como se recoge en un documento de 1490 que establecía también la limosna que se debía entregar por las sepulturas situadas en esta panda ${ }^{47}$ : el abad Pablo Martínez de Uruñuela, con el consentimiento de la comunidad monástica, señala cómo en el claustro o galería «que se llama de los Caballeros... están sepultados reinas y caballeros de alta sangre e de títulos y otros muchos caballeros en títulos, señores de vasallos», y que la parte que está más cerca de la capilla de los reyes (es decir, los pies de la iglesia), y precisamente por esta cercanía, «es habida por mayor y de más dignidad en que yacen sepultadas dos reinas y don Diego el Bueno y su mujer doña Toda». Esta primera zona comprende la pared desde dicho sepulcro de don Diego hasta la puerta que entra a la escalera de cara$\mathrm{col}^{48}$, toda la pared colindante con la iglesia, $\mathrm{y}$ «es el primero y más alto grado», de forma que sólo podrían ser enterrados allí personas de la familia real o de «caballero de título», pagando 30.000 maravedíes, "atento que los allí yacen sepultados para cada año dieron mucha mayor cantidad». Esta frase hace referencia a las generosas donaciones para aniversarios realizadas por algunos de estos nobles.

En este primer grado se incluyen los cinco nichos o arcos ocupados por don Diego López de Haro, los Mendoza, los Manrique, los Jiménez de Cabredo y los Salazar, según señala el cronista Juan de Salazar ${ }^{49}$; y así aparecen también recogidos en el plano de Francisco de Odraizola realizado en 1596, ${ }^{50}$ aunque hay un roto en el espacio correspondiente a los Cabredo.

45 Ibídem: 50. Pablo Martínez de Uruñuela fue abad entre 1486 y 1505. En el plano del monasterio elaborado por Odraizola se la describe como «Capilla de San Antón y entierro de los monjes».

46 Español 2003: 24.

47 Castañeda 1929: 68-70. Madrid: Tipografía de Archivos; Yepes 1960: 99-100, quien señala que este orden de jerarquización «lo vemos practicado en nuestros tiempos", pero que es más antigua como demuestra este documento; Salazar 1987. Lo recoge Ruiz Maldonado 1996: 103-104, nota 30.

48 Esta escalera que se acabó en tiempos del abad Pablo Martínez de Uruñuela (como señala AHN, Clero, leg. 2952, Libro 20 de los censos de Santa María de Nájera) era para que los monjes subieran al coro alto de la iglesia, estando la entrada por la capilla de San Juan y la salida al claustro bajo la puerta antes Ilamada de San Juan; esta escalera se deshizo en 1771 y en su hueco se hizo la capilla de Santa Gertrudis (ibídem).

49 Salazar 1987: 186.

50 AHN, Mapas, planos y dibujos de Clero, no 63.
En esa jerarquización del Claustro de los Caballeros, el segundo grado correspondía al espacio comprendido desde los pies de la sepultura del citado don Diego López de Haro hasta el pilar que está en la cabecera del sepulcro de un tal Gil García que, por desgracia, no podemos localizar ahora. Aquí se enterraría a "caballeros y nobles señores de vasallos» y sus descendientes, pagando 20.000 maravedíes por ello.

$\mathrm{Y}$, finalmente, un tercer grado, desde dicho pilar $\mathrm{y}$ cabecera del sepulcro del citado Gil García «fasta la esquina de la obra de crucero de la Iglesia mayor y del cantón que vuelve para la otra claustra a donde se acaba la dicha claustra de los caballeros»; este espacio está destinado a "hombres fijosdalgo de todos cuatro costados», que darían 10.000 mrs.

El segundo grado parece corresponder a sepulturas realizadas en el suelo, pues señala Salazar ${ }^{51}$ que éste estaba «cuajado de sepulturas, con sus lápidas, armas y letreros de otros muchos linajes nobles de Vizcaya y Montaña», entre los que cita a los Montoya, Castillos, Pereas, Gamarras y otros. Posiblemente coincidiría en el suelo con los arcos de los altos linajes en la pared. ${ }^{52}$

Finalmente, el tercer grado de los enterramientos corresponde a los tres nichos que aparecen en el plano de Odraizola en la esquina que forman los dos claustros, el de los Caballeros y el de los Mártires; o, como describe el mencionado documento, la parte final de la galería desde la puerta de acceso al crucero, la puerta de los monjes, hasta el inicio del claustro de los Mártires.

Termina el documento estableciendo que «otras personas de cualquier estado o condición que sean no puedan ser sepultadas en toda la dicha claustra, ni en parte alguna de ella»..$^{53}$ Otros claustros, el de los Confesores y el de las Vírgenes, estarían abiertos a personas de origen menos elevado; y así, en el plano de Francisco de Odriozola, se indica sobre el Claustro de los Confesores que «en todos es-

\section{Salazar 1987: 186.}

52 Garrán 1909: 63, afirma que en el siglo xIX se arrancaron las losas del pavimento "para ponerlas en las calles por aceras».

53 La práctica de jerarquización de los espacios destinados a sepulturas, y consiguientemente del dinero que se pagaba por ellas, es semejante en otros lugares. Sirvan de ejemplo las capillas del claustro de la catedral de Toledo según se refleja en un estatuto capitular de 1423, al establecer que para el entierro en la parte principal del mismo, donde estaban las sepulturas más prestigiosas, se pagarían 800 mrs., mientras que en la segunda y tercera fachadas sólo 400 (Torija Rodríguez 2014: 298-299. La gran diferencia de las tasas respecto al claustro de Santa María de Nájera se debe con toda seguridad a que en la catedral de Toledo había numerosas capillas y entierros más notables dentro del mismo templo. También podemos comparar estas tasas de sepultura con las establecidas casi un siglo más tarde, en 1579, para la Capilla de la Cruz de Nájera, edificada fuera del templo monástico por estos años como consecuencia de los numerosos pleitos que desde hacía muchos años se habían desarrollado entre el monasterio y los capellanes. En este caso se pagaban 10.000 mrs. por las sepulturas perpetuas situadas en la nave mayor, además de 500 mrs. para la lápida; en el caso de que no fuese sepultura perpetua, sólo se pagarían $1.000 \mathrm{mrs}$. y al cabo de un año la propiedad quedaba para la iglesia (Archivo Histórico Nacional, Clero, leg. 3024). En fecha cercana a ésta, el año 1577, también se establecieron las tasas de sepultura en la iglesia de Santa María de Sojuela, perteneciente al monasterio. En este caso se hacía una gradación en 8 hileras definidas por la cercanía al altar mayor, de forma que los enterrados en las dos primeras filas pagaban $1.000 \mathrm{mrs}$. (aunque la primera estaba reservada a los clérigos), y a medida que se alejaban del altar mayor iba bajando el precio a 500, 400, 300, 200, 100, 51 y 34 mrs. respectivamente (Archivo Histórico Nacional, Clero, leg. 2893). 
tos claustros se entierran los feligreses y en las hornacinas que están señaladas la gente principal». ${ }^{54}$ Y Juan de Salazar ${ }^{55}$ insiste en esta información, al decir que en ellos estaban en-terrados algunos linajes nobles, quizás por no haber sitio en el de los Caballeros o «por otras razones», como ocurre con los López de Arcos, Arbizu o Guineas, «las cuales están acompañando y como haciendo corte a las personas reales allí enterradas».

\section{El panteón de los Haro}

Uno de los linajes que eligieron el monasterio najerense como lugar de entierro es el de los López de Haro, familia que tenía en esta región el centro de su dominio y cuyo prestigio aumentaba, sin duda, por compartir el lugar de entierro con los reyes navarros. Esta vinculación llegó a su culminación a principios del siglo XIII con Diego López de Haro II, pero parte, al menos, de su tía Toda López, hija de Diego López de Haro I, de la que consta fue enterrada allí en los primeros años del siglo XII, como declaró su hija María López, al donar en 1138 diversos bienes a este monasterio «ubi mater mea tumulata requiescit». ${ }^{56}$ Unos años antes, en 1121, habían sido estas dos mujeres, doña Toda y su hija María, las que entregaban una heredad y una casa para alumbrar el altar de Santa María de Nájera por las almas de sus familiares difuntos: los padres de doña Toda, el conde don Lope y la condesa doña Toda, y de su marido y padre, respectivamente, Lope González Girón. ${ }^{57}$ Esta donación demuestra la vinculación de oración por los difuntos que acompañaba la elección del monasterio como panteón familiar. El cronista Juan de Salazar ${ }^{58}$, aludiendo a estos favores, afirma que hicieron «muchas donaciones y tan grandes, que parecen efectos de personas reales, porque dio muchos monasterios, lugares, sernas y otras heredades»; también afirma que doña Mayor estaba enterrada en el monasterio, "aunque no consta si en la Capilla Real o en el Claustro de los Caballeros", dato que parece verídico, y desde luego creíble, pero del que no hay ninguna otra referencia.

Los sepulcros de don Diego López de Haro y de su segunda mujer doña Toda Pérez de Azagra se encuentran en el Claustro de los Caballeros, en la zona más cercana a la iglesia y al panteón real, lugar privilegiado por excelencia, como señalaba el documento de 1490 antes mencionado. Don Diego, X señor de Vizcaya, era propietario de un amplio dominio territorial en Castilla la Vieja, La Rioja, Álava y Guipúzcoa; casado en primeras nupcias con Urraca, hermana del rey Fernando II de León, y en segundas con Toda Pérez de Azagra o de Castro, tuvo una notable participación en la batalla de las Navas de Tolosa ${ }^{59}$ y fue designado tes-

54 Archivo Histórico Nacional, Clero, Planos, no 63. Entre las diversas obras que realizó este cantero se recoge que en 1597 «a echo en el pano de la parte de las peñas debaxo las capillas viexas seis entierros con su hornato, y el uno dellos está en la pared postrera»; se refiere al Claustro de los Confesores, donde estaba la capilla de la reina Mencía o de la Vera Cruz, señalando también que hizo en esta misma pared cuatro ventanas para dar luz a esta capilla (Archivo Histórico Nacional, Clero, leg. 2963 (1).

55 Salazar 1987: 187.

56 Cantera Montenegro 1987: doc. 50.

57 Ibídem: doc. 33.

58 Salazar 1987: 186.

59 Sandoval 1614: 63, dice que tuvo «el señorío y gobierno de Nájera, Logroño, Rioja, Bureba, Castilla Vieja, Trasmiera, Asturias y la tamentario por el monarca Alfonso VIII, aunque finalmente falleció antes que el testador. ${ }^{60}$

Fue un gran protector del monasterio de Nájera en el momento en que el mismo empezaba a sentir las dificultades económicas que caracterizan su historia en los tiempos siguientes. Así, el conde y su mujer doña Toda realizaron varias donaciones a favor del mismo: en 1200 y 1201 entregaron varios collazos, con sus solares y pertenencias; y en 1214 , compadecidos por la pobreza de los monjes, algunos de los cuales estaban enfermos, donaron otros collazos y diezmos y una viña para atender a la enfermería, el vestuario e iluminación del altar de Santa María. Al año siguiente la donante fue doña Toda, ya viuda, entregando la villa de Torrecilla sobre Alesanco y las heredades y collazos que poseía en Azofra y Alesanco para que los monjes celebrasen su aniversario y el de su marido, como lo hacían con los reyes: «in perpetuum annis singulis anniversarium integrum et plenarium sicut pro regibus». ${ }^{61}$

Los sepulcros de los esposos son una verdadera joya del arte funerario. El de don Diego ${ }^{62}$ se acoge a un arcosolio renacentista situado junto a la puerta de acceso a los pies de la iglesia y en el que se representa el escudo de la familia Haro (dos lobos con un cordero sangrante en la boca), posiblemente del siglo XVI. Delante de él se colocó después de los años 60 del siglo xx el túmulo de su mujer doña Toda, sobre cuatro basas modernas rectangulares; en este caso hay una inscripción que identifica a su titular y la fecha del fallecimiento, 13 de febrero de 1216.

Según los cronistas Sandoval, Yepes y Salazar, el sepulcro de don Lope tenía ciertos epitafios que identificaban el túmulo funerario ${ }^{63}$; aunque se han perdido, no se duda de la identidad del allí enterrado por esta tradición cronística de personas que pudieron ver el monumento antes de su deterioro. Se trata de una caja prismática rectangular ${ }^{64}$ cuya tapa excede en longitud a la de la caja, por lo que hay que suponer que no corresponde a ella, representando la figura yacente del finado, muy deteriorada, y que corresponde al estilo gótico del siglo XIII, aunque fue parcialmente rehecha en la primera mitad del XVI; vestido ricamente según corresponde a su estatus, apoya sus pies en un mastín. La cabecera de la

mitad de Burgos, Laredo, Velorado y Granon, todas plazas de mucha importancia y honor». El mismo cronista afirma (Sandoval 1614: 68) que entregó al monasterio las banderas que ganó en esta batalla, y que solían ponerse en lo alto del coro y crucero el día en que se celebraba en el monasterio la fiesta del Triunfo de la Cruz y describe así a este caballero: «fue uno de los señalados varones que ha tenido nuestra España en valor, gran capitán y cristianísimo príncipe, y así apreciaron los Reyes de trabar parentesco con él, casando con sus hermanas» (Sandoval 1614: 63). Diago Hernando 1994: 775, señala cómo el linaje Haro, uno de los más destacados de la nobleza vieja castellana, era la principal instancia de poder en un amplio sector del noreste del reino de Castilla, en concreto La Rioja.

60 González 1969: 212, Vol. I.

61 Cantera Montenegro 1987: I, 315-316; y docs. 102, 104, 113 y 114 , respectivamente. En este último documento, doña Toda establecía que la celebración del aniversario por su marido fuese el día 17 de septiembre y el suyo el día de los santos Fabián y Sebastián, el día 20 de enero; sabemos que en el siglo xv se celebraba el de don Lope este día de san Sebastián (AHN, Clero, leg. 2952, Libro segundo de censos).

62 Ruiz Maldonado 1996: 92 y 103.

63 Sandoval 1614: 70-72; Yepes 1960: III, 101-102; y Salazar 1987: 183-185.

64 Descripción de este sepulcro y del de su mujer doña Toda en Moya Valgañón 1986: 58-59; y Ruiz Maldonado 1996: 106-111. 
caja tiene una cruz griega y los pies un lobo de gran tamaño, pero sin el cordero en la boca propio del escudo de la familia. El costado adosado al muro se decora con una sencilla cruz, mientras que en el frente se representa el entierro del noble, con el sarcófago en el centro y acompañado por diversos personajes: varios monjes, entre ellos los encargados de cerrar el sarcófago; el cortejo de los seglares, tres hombres y tres mujeres, ricamente vestidos, a la izquierda, mostrando los gestos propios de manifestación de dolor (mesarse los cabellos o apretarse las mejillas); y la comitiva de los clérigos, encabezada por un obispo o abad mitrado que lee las oraciones de un libro que sostiene un monje, y formado por cuatro monjes, uno de los cuales porta hisopo y acetre.

El sarcófago de su mujer, doña Toda Pérez de Azagra, se compone de caja rectangular y tapa a dos vertientes; adosado al arcosolio en el que se encuentra el sepulcro de su marido, sólo se pueden ver tres lados del mismo. El costado mayor y los pies están decorados con retícula de flores, aves y monstruos, y la cabecera con el lobo pasante de los Haro. En la tapa se representan cruces en la vertiente posterior, aves en la cabecera y los pies; y en la vertiente anterior, sobre un borde con animales fantásticos, las exequias de la finada: el sarcófago con inscripción que identifica a doña Toda y la fecha del fallecimiento, está situado a la derecha; junto a él, en el extremo derecho, se representa a un obispo en actitud de bendecir y presidiendo la ceremonia fúnebre, y junto a él dos monjes, uno que porta un libro y otro una cruz procesional. Siguiendo el cortejo fúnebre que encabeza el obispo mencionado, por encima del sarcófago se representa a otros dos monjes y dos monjas, las cuales usan amplias tocas semejantes a las de las monjas cistercienses de Cañas $^{65}$; tras ellas y a los pies del sarcófago, aparecen tres nobles damas haciendo visibles gestos de dolor y tres caballeros plorantes.

Yepes y Salazar ${ }^{66}$ afirman que están enterrados en este Claustro de los Caballeros, el hermano de Diego López II, Martín López de Haro, y sus hijos, el conde don Lope Díaz de Haro II, don Pedro y doña Berenguela. Si de ninguno de ellos hay constancia documental o artística de su entierro, en el caso de doña Berenguela conocemos el establecimiento de tres capellanías en Santa María de Nájera, dos en beneficio de su alma y una de las de sus padres (el citado don Lope y Urraca Alfonso, hija de Alfonso IX de León ${ }^{67}$, fundación que podría acompañar la solicitud de entierro en el monasterio.

65 Este monasterio de bernardas de Cañas fue fundado por Lope Díaz de Haro Il y su mujer Aldonza Ruiz de Castro, consolidándose bajo el abadiato de su hija Urraca (1225-1262), cuarta abadesa del cenobio, que gozó de fama de santidad; su sepulcro, conocido como el de la Beata, es una magnífica muestra del arte funerario gótico de mediados del XIII (Ruiz Maldonado 1996: 113-124); en él se representan precisamente esas monjas de amplias tocas, muy semejantes a las del sarcófago de doña Toda que comento.

66 Yepes 1960: III, 102; y Salazar 1987: 185-186.

67 Cantera Montenegro 1987: doc. 161. Garrán (1909: 70) supone que los restos de estos miembros de la familia, recogidos en diversas épocas, «descansan ahora juntos, en la grandiosa bóveda subterránea de dicho mausoleo». Domingo Hergueta añade a esta lista de miembros del linaje enterrados en el monasterio a Lope IV Díaz de Haro, fallecido en 1170 y del que dice fue enterrado en el Claustro de los Caballeros, y Alfonso López de Haro (Hergueta 1969: 81 y 84).

\section{La capilla de la Vera Cruz o de la reina doña Mencía}

Hay otro espacio funerario vinculado en principio a la familia Haro, la capilla de la reina Mencía de Portugal o de la Vera Cruz, situada en el ángulo norte del claustro de los Confesores (ala oeste del claustro monasterial). En la actualidad es una pequeña capilla de planta rectangular y en mal estado de conservación por las vicisitudes vividas desde la desamortización del siglo XIX y la humedad, de tal manera que en 1909 estaba en ruinas ${ }^{68}$; pero en sus orígenes ocupaba toda la extensión de este ala oeste, y por ello Sandoval la describía como «una rica Capilla casi igual con la de los Reyes sus deudos y del tamaño de una buena Iglesia». ${ }^{69}$

Reducida ahora a una sexta parte de su tamaño original, alberga cinco enterramientos y fragmentos de relieves de diversas épocas encontrados en el monasterio. En el centro de la capilla se encuentra el sepulcro de la reina, flanqueado por los de sus hermanos don Diego López de Salcedo y don Lope Díaz de Haro, obispo de Sigüenza, todos ellos góticos, de la segunda mitad del siglo XIII; en sendos lucillos están los de los caballeros Garcilaso de la Vega, de 1200, y Gómez Manrique de Lara, renacentista. ${ }^{70}$

La construcción de una capilla funeraria propia y el establecimiento de unas capellanías, como ocurre en este caso, son un signo distintivo de poder, una forma de mostrar la perpetuación de la memoria individual y del linaje. ${ }^{71}$ Una muestra visible de ello es la proliferación de emblemas heráldicos de los Haro en los sepulcros de los tres hermanos.

Doña Mencía ${ }^{72}$ era hija de Lope Díaz de Haro Cabeza Brava y de la infanta leonesa Urraca Alfonso, hija de

68 Moya Valgañón 1989: 72. Señala este autor cómo tras la exclaustración la iglesia sirvió como parroquia de San Jaime desde 1845 y diversas dependencias monasteriales se destinaron a diversos fines municipales, llevándose a cabo derribos como el de las dependencias sobre el área cementerial pegada a las peñas, que contribuyó al hundimiento de esta capilla de la Vera Cruz. También señala las labores de restauración llevadas a cabo entre 1947 y 1957 que supusieron, entre otras cosas, el saneamiento de la zona colindante a la peña, dejando expedita el área cementerial situada entre ella y el claustro.

69 Sandoval 1614: 56. Posiblemente se refiere a la parte desaparecida de la capilla, la zona situada cerca del panteón real, la noticia que transmiten Yepes (1960: 101) y Salazar (1987: 183), respecto a algunos restos encontrados al derribar una parte de dicha capilla para edificar "el cuarto nuevo que está arrimado a las peñas, y toca con la capilla real, donde se hallaron "sepulturas con mucha autoridad», en ataúdes forrados de terciopelo y con clavos dorados, conservándose los cuerpos «casi enteros». Podemos aventurar que estos cuerpos pertenecían a la familia Haro, tratándose posiblemente de los miembros del linaje recogidos por los cronistas y que he señalado antes.

70 Ruiz Maldonado, 1996: 134-135. Sandoval (1614: 72-73) afirma que en esta capilla estaba enterrada también doña Urraca Díaz, hija de Lope Díaz de Haro y casada con el rey Fernando II de León, atribuyendo a ella, y no a doña Mencía, la construcción de la capilla; Yepes (1960: 100) y Salazar (1987: 183) señalan que esta atribución es un error, pues esta doña Urraca estaría enterrada no en esta capilla sino «en un arco cabe la Santa Cueva».

71 Yarza Luaces 1988: 68-69. La misma idea se manifiesta en varios trabajos recogidos en el libro Bougard, La Rocca y Le Jan (dirs.). 2005. También Aventin (2001: 391) señala cómo la ejecución de los testamentos, especialmente los legados piadosos, era una forma de mantener la presencia de los muertos entre los vivos, al tiempo que se resalta la responsabilidad de éstos respecto a la salud eterna de sus familiares fallecidos.

72 Sobre su vida, Ruiz Maldonado 1996: 135-138. 
Alfonso IX ${ }^{73}$; por su padre era nieta de Diego López de Haro el Bueno. Se casó dos veces; la primera, en 1234, con Álvar Pérez de Castro, primo lejano suyo, que falleció en 1239. Por su segundo matrimonio en 1241 con el rey Sancho II Capelo se convirtió en reina de Portugal; pero el matrimonio, que no tuvo descendencia, se vio envuelto en la guerra civil que desató el hermano del rey y su sucesor, Alfonso III. Los esposos eran parientes en cuarto grado y el matrimonio no contó con la pertinente licencia del papa Inocencio IV, motivo que fue también utilizado contra el rey en la discordia civil. Finalmente, Sancho perdió el trono de Portugal y, refugiado en Toledo, murió en 1248. Mientras tanto, su mujer permaneció retenida en Ourén por su cuñado, ya rey de Portugal. Regresó a Nájera, la casa de sus padres, en torno a 1255 y falleció entre 1271 ó 1272, siendo enterrada en la mencionada capilla que ella fundó.

Para que se rezara por su alma, la reina había ordenado en su testamento el establecimiento de cuatro capellanías en dicha capilla, para que se cantaran "missas por su alma cada día fasta la fin del mundo". ${ }^{74}$ Conocemos esta fundación a través del documento de diciembre de 1275 por el cual cumplían la voluntad de la reina su hermano Diego López de Salcedo y fray Diego Ruiz, como sus mansesores y cabezaleros; en él establecen que dos de los capellanes serían monjes del cenobio najerense y los otros dos clérigos seculares; los designaría el prior de Santa María de Nájera, debiendo cambiarlos cada cinco años, contando siempre con consejo y la autorización del citado don Diego y, cuando él falleciese, del guardián de los franciscanos de Belorado. El prof. Reglero de la Fuente hace notar que algunas de estas condiciones reflejan una cierta desconfianza hacia el cumplimiento de los compromisos por parte de los monjes, especialmente el hecho de que la designación de los capellanes no fuese competencia exclusiva del prior najerense. $^{75}$

Don Diego de Salcedo establecía en el mismo texto otras dos capellanías en beneficio de su hermano don Lope, obispo de Sigüenza, y de él mismo; atendidas por dos monjes del cenobio, se vinculaban al altar de Santiago, en el caso de la capellanía de don Diego, y al de san Nicolás, sito en la capilla de la reina doña Mencía, en la del obispo. ${ }^{76}$

73 Salazar 1987: 178, la hace hija de su segunda mujer Toda de Santa Gadea y Salcedo, de forma que sería hermana, y no hermanastra, de los dos enterrados con ella.

74 Cantera Montenegro 1987: doc. 189. Reglero de la Fuente 2008: 277 considera probable que estén en relación con esta capilla los paños labrados con lobos blancos, emblema de la familia, inventariados en el monasterio en el siglo XIV.

75 Reglero de la Fuente 2014: 82. También considera que encargar la supervisón del cumplimiento de las obligaciones de las capellanías indica la situación de pobreza del monasterio, que hacía temer el desvío de los bienes adscritos a dichas capellanías a otros fines distintos.

76 Reglero de la Fuente 2014: 116, señala que la advocación de este altar dedicado a san Nicolás, patrono de los escolares de las catedrales, subraya la condición episcopal de don Lope. La fundación de todas estas capellanías incluidas en el documento se apoyaban en unas generosas dotaciones económicas que harían posible su mantenimiento. En el caso de las correspondientes a doña Mencía, el prior najerense recibió 8.000 mrs. para comprar una heredad que proporcionase la renta necesaria; para las otras dos, don Diego entregó 2.500 mrs. Los capellanes que atenderían las capellanías de dona Mencía recibirían cada uno de ellos 100 mrs. al año en el caso de los monjes y 200 en el de los clérigos seculares; los monjes encargados de las otras dos, $50 \mathrm{mrs}$. al año.
El sepulcro de la reina doña Mencía, muy deteriorado por ser de piedra arenisca, se halla en el centro de la capilla, sobre seis leones echados, de los que solo se han tallado las cabezas y las patas delanteras. Dispone de una estatua yacente en la tapa, recostada sobre dos almohadones y elegantemente vestida, de acuerdo con su elevada posición social. En la caja hay decoración heráldica con once escudos, alternando los propios de los López de Haro con los de la casa real portuguesa. ${ }^{77}$

Otro de los sepulcros que se encuentran en esta capilla es el de don Lope Díaz de Haro, hijo de don Lope Díaz de Haro Cabeza Brava y de Toda Salcedo de Santa Gadea, hermanastro, por tanto, de la reina Mencía y fallecido poco antes que ella, en mayo de 1271; fue obispo de Sigüenza desde 1269 y fundó la cátedra de Gramática de Atienza. ${ }^{78}$ Su sepulcro en la actualidad está adosado al muro este de la capilla, a la izquierda del de la reina; tiene estatua yacente revestida con las ropas episcopales, que podría ser obra del mismo artista que realizó el sepulcro de su hermana; la caja está blasonada con los escudos de los Haro en el costado mayor, un lobo heráldico en la cabecera y una cruz griega flordelisada a los pies. ${ }^{79}$

Por su parte, Diego López de Salcedo parece el hermano más allegado a la reina Mencía, pues fue su ejecutor testamentario; caballero cercano a los monarcas Alfonso X y Sancho IV, fue merino mayor de Castilla y falleció en 1294. Su sepulcro, en muy mal estado de conservación, se encuentra en el muro oeste de la capilla, junto al de Garcilaso de la Vega, aunque éste no era su emplazamiento original ${ }^{80}$; en la tapa se encuentra representado el caballero con las vestiduras propias de su estado nobiliario (saya, pellote, capa con fiador y tocado cilíndrico), además de espada y espuelas, teniendo un perro echado a sus pies; la caja tiene decoración heráldica.

Fray Prudencio de Sandoval ${ }^{81}$ afirma que dentro de la sepultura estaba el cuerpo "que vieron muchos que yo cognoscí aforrado en terciopelo verde y clavos dorados». También afirma que otros miembros de la familia estaban enterrados en el monasterio, aunque no indica dónde, en «sepulturas muy antiguas con cuerpos en ataudes aforrados en telas de oro y seda y clavos dorados y en las cabezas destos clavos los lobos cebados». El cronista afirma que estos familiares son el conde Lope Díaz de Haro, hijo del citado don Diego, su mujer doña Urraca Alfonso, hija del rey Alfonso IX de León, y su hija Berenguela López. La vinculación con el monasterio de este matrimonio y de su hija se puede comprobar por la donación que hizo doña

77 La descripción detallada de este sepulcro en Ruiz Maldonado 1996: 140-141. Fray Juan de Salazar lo explica así: «tiene encima el vulto de la reina muy revelado con el traje así en el vestido como en el tocado, como se usa ahora en Vizcaya, el uno lleno de pliegues, y el otro muy levantado, bien conforme a lo que se vió en una ocasión que se abrió el sepulcro, porque se afirma que el tocado que tenía en la cabeza envolvía más de cincuenta varas de cendal delgadísimo y que de la parte más inferior de él que tocaba al cuello le bajaba una como estola cuyos extremos estaban guarnecidos de oro y piedras preciosas que es el mismo traje y forma que se muestra en la figura de afuera» (Salazar 1987: 178). Descripción semejante hace Yepes 1960: III, 103.

78 Ruiz Maldonado 1996: 93, 141 y 148.

79 Ibídem: 148 y 142.

80 Sobre este sepulcro, ibídem: 143-144.

81 Sandoval 1614: 82 y 56. 
Berenguela en 1266 para fundar capellanías por su alma y por las de sus padres. ${ }^{82}$

En la misma capilla de la Vera Cruz se encuentra un sepulcro románico reutilizado en el siglo XIV para acoger el cuerpo del caballero Garcilaso de la Vega, fallecido en 1367 en la batalla de Nájera combatiendo a favor de Enrique de Trastámara; hijo del canciller del mismo nombre, estuvo casado con María de Cisneros. ${ }^{83}$ Su entierro en el monasterio najerense ratifica la veracidad de la noticia que nos transmite el cronista Gregorio de Argaiz: el prior Guido, a petición de Pedro I, vencedor de la batalla, dio sepultura en el monasterio a algunos de los caballeros fallecidos en la misma. ${ }^{84}$

El sarcófago, realizado en torno a 1200, tiene forma trapezoidal y tapa a doble vertiente; estando exento en un primer momento, en la actualidad se encuentra pegado a la pared de un nicho construido bajo arcosolio del siglo XIV, el momento de su reutilización; y, como los anteriores, se encuentra en mal estado por los destrozos sufridos en la capilla. ${ }^{85}$ En el único costado visible de la caja se representan escenas de la Pasión: el prendimiento, la flagelación y la crucifixión. En la vertiente anterior de la tapa hay dos personajes con filacterias, junto al tema central que es la resurrección (el ángel sobre el sepulcro en diálogo con las Marías y los soldados, dormidos); ambas escenas se encuentran separadas por un árbol estilizado con aspecto de columna, que también aparece separando el grupo de las mujeres en dos. En la vertiente posterior de la tapa se representa a los apóstoles dialogando por parejas y portando filacterias; y en el frontispicio, una arpía de doble cola de dragón. En la moldura de separación de las vertientes de la tapa se labró en el siglo xIV con caracteres góticos la inscripción «Aquí yace Garcilaso de la Vega».

Unos años después de haber sido enterrado este caballero en el cenobio najerense, su hija doña Leonor de la Vega, ya viuda de Diego Hurtado de Mendoza, almirante mayor de Castilla, hizo una generosa donación al monasterio, para fundar una capellanía por el alma de su padre; los monjes asumían la obligación de decir una misa rezada a diario por el alma del caballero, pero también por la de la donante cuando falleciese (mientras tanto debían rezar por su vida) y por todos sus difuntos. ${ }^{86}$

82 Cantera Montenegro 1987: doc. 161. Aunque es cierto que la familia Haro parece ir desvinculándose del cenobio najerense a favor de las Órdenes mendicantes, aún aparecen algunas donaciones que tienen a Santa María de Nájera como destinataria; así, María Díaz de Haro, hija de Diego López de Haro V, dejó en su testamento una manda de 2.000 mrs. para la obra del monasterio y otros 1.000 para la pitanza de los monjes, la más alta de las destinadas a monasterios y conventos, aunque el entierro dispuso se realizase, como el de su padre, en el convento de San Francisco de Burgos (Estepa 2002: 382) y Reglero de la Fuente 2014: 85 .

83 Ruiz Maldonado 1992: 200-201.

84 Argaiz 1675: $382 \mathrm{v}-383 \mathrm{r}$.

85 Ruiz Maldonado 1992: 201-205; y, de forma más breve pero muy precisa, en Álvarez-Coca González, 1978: 39-40.

${ }^{86}$ Archivo del Hospital Tavera (Toledo), Cartulario de Santa María de Nájera, II, fols. 173 v-175 v (carta de procuración del monasterio a favor de uno de los monjes para recibir en nombre de la comunidad esta donación, de 16 de septiembre de 1405; en este documento señalan los monjes que la donación se había realizado unos antes, viviendo aún Diego Hurtado de Mendoza, marido de doña Leonor, aunque en ese primer momento la cantidad era de 40 fanegas de trigo, todas ellas en sus
El conjunto funerario de la capilla de la Cruz se completa en la actualidad con el sepulcro de D. García Manrique de Lara, hijo del primer duque de Nájera y canónigo y tesorero de Toledo, fallecido en 1568; situado en un arcosolio de medio punto con escudo, tiene estatua yacente. ${ }^{87}$ Fray Juan de Salazar habla de "una urna muy bien labrada en que están sus cenizas, y encima de ella un vulto con sus insignias y armas todo de relieve», destacando que su predilección por este monasterio le llevó a pedir ser enterrado en él sobre la iglesia de Toledo a la que estaba vinculado ${ }^{88}$; en este hecho también tenemos que ver el deseo de resaltar la perduración del linaje después de la muerte. No es posible saber si su entierro se produjo ya en esta capilla o, quizás lo más probable, en el espacio reservado a su familia en el Claustro de los Caballeros.

\section{Otros enterramientos en el claustro}

Muchas de las sepulturas conservadas en el claustro son posteriores al período aquí analizado y sólo tres corresponden al siglo xv: en el claustro oeste o de los Confesores, la de Juan Manuel, fallecido en 1485; en el sur o de los Caballeros, la de Pedro González Velorado y su hijo Alonso González de Velorado, fallecidos en 1464 y 1517, respectivamente; y en el este o de los Mártires, la de Pedro Díaz y su mujer Juana García de la Puente, de fines del xV o principios del XVI. ${ }^{89}$

Por la documentación conservada sabemos del entierro de algunas personas en el claustro del monasterio, pero no consta ninguno de estos nombres grabados en las lápidas, como tampoco se encuentran entre las inscripciones conservadas los de los transmitidos por las fuentes escritas. Por otra parte, hay que destacar que las referencias documentales de entierros en el cenobio corresponden

rentas de Pedrosa de Río Úrbel) y 173 v-178 r (donación de doña Leonor, de 3 de octubre de 1405: 50 fanegas de trigo en las rentas que tiene en Valle de Santibáñez y en Pedrosa de Río Úrbel). El 18 de noviembre de 1409 (fol. 227 r-v) la citada doña Leonor volvía a dirigirse a «los señores et amigos monges de Santa María de Nágera» para eximirles de presentar fiadores por las fanegas entregadas para esta capellanía. Estos documentos están reseñados en Cantera Montenegro 2011: docs. 20, 21 y 53 , respectivamente.

Fray Juan de Salazar afirma que la primera donación de doña Leonor, a la que se hace referencia en el primero de los documentos citados, fue hecha en 1398 y que los monjes se obligaron a decir cada año un aniversario por el alma del citado Garcilaso de la Vega, afirmando que cuando él escribía «hácese así con toda autoridad» (Salazar 1987: 179).

87 Moya Valgañón, 1986: 57.

88 Sandoval 1614: 179-180. Señala que dejó 200 ducados para que se labrase el sepulcro y otros 100 para el traslado del cuerpo hasta el monasterio; además dispuso la entrega de una renta de 22 ducados para un aniversario, así como «una grande librería de todas facultades, rica y curiosamente encuadernados todos sus libros, en becerro y folio dorado, esculpido su nombre en una y otra tabla de cada uno de ellos».

89 Moya Valgañón 1986: 56 y 59 describe las inscripciones de estas sepulturas, recogiendo con detalle sus inscripciones: De la primera sepultura: Esta sepultura es de Juan Manuel y de sus sucesores fallecio a 12 de setiembre de 1485. La segunda: Aqui yacen sepultados Pedro Gonçalez Velorado que fino año de 1464 y Alonso Gonzalez de Belorado su hijo que fino año de 1517 y Alonso Gonzalez de Velorado su nieto que mando hazer este retablo ano de 1619... La tercera: Aqui yase Pero Diez y su mujer loana Garcia de la Puente; esta inscripción se encuentra en una cartela que sujeta un ángel y hay también un escudo tajado de árbol y cabeza de buey. 
hasta el siglo XIV a personas vinculadas a linajes nobiliarios, momento en que se abre el espectro social de los solicitantes y testadores.

La primera noticia de un entierro en el monasterio, y que parece indudable sería en el claustro, data de 1123 cuando Jimena Pérez, viuda del senior García Aznárez, confirmaba el prohijamiento que, por no tener hijos, había realizado tiempo atrás el matrimonio a favor de los monjes cluniacenses de Santa María de Nájera; y en este momento, ya viuda, Jimena pedía que al fallecer «sepeliant me in Nazara iuxta dominum meum ${ }^{90}$, referencia explícita al entierro de su marido en el monasterio, al tiempo que solicitaba el suyo para cuando llegara el momento.

Consta también que fue enterrado en el monasterio Diego Jiménez de Cabredo, perteneciente a una «casa ilustre», como la califica el cronista Juan de Salazar. La noticia de este hecho nos la da doña Guiomar, su viuda, quien, al donar en 1193 una serna en Sorzano, declara que su marido estaba enterrado en el monasterio; la donación la hacía a favor de la sacristanía, con objeto de que hubiese siempre una candela encendida ante el altar de Santa María por la remisión de sus pecados. ${ }^{91}$ La localización de este sepulcro podría ser el panteón familiar situado, como ya he señalado antes, en el Claustro de los Caballeros, según hizo constar el ya citado cronista Juan de Salazar.

Don Sancho de Loriz y su mujer doña Toda Ortiz son protagonistas de un acuerdo con el prior y el monasterio najerenses en $1201^{92}$ : el cenobio les arrendaba una casa en «Certun» para que la poseyesen libremente toda su vida, así como la villa de Torseca, que debían hacer poblar ese mismo año. La contrapartida del arriendo, aparte del censo establecido por la casa, era el entierro en el monasterio: «ego dompnus Sancius de Loriz et uxor mea domna Toda Ortiz, pro amore quem vos prior et conventus nobis facitis, corpora nostra Nagarensi sepelienda monasterio mandamus». Del documento se deduce que en ese momento el matrimonio no tenía hijos, pero se reguló detalladamente que, si posteriormente nacía alguno, la citada casa debía volver al monasterio al fallecer los cónyuges.

Tras estas noticias y las referentes a la familia Haro, ya señaladas, nos encontramos con un vacío documental de siglo y medio, hasta el último tercio del XIV, momento a partir del cual se abre el abanico social de los enterrados en Santa María de Nájera y se hace mención explícita al claustro como lugar de entierro.

En septiembre de 1373 Martín Fernández de Valderrama, hijo de Martín Ruiz, redactó testamento ${ }^{93}$, por estar enfermo; en él disponía ser enterrado en el claustro «do el prior y

\footnotetext{
90 Cantera Montenegro 1987: doc. 34.

91 Ibídem: doc. 87; dice explícitamente al hablar de él «cui sit requies» en el monasterio. Salazar (1987: 186) afirma que la enterrada en el monasterio es la madre de la donante; en la copia del documento conservada en el Archivo Histórico Nacional aparece un paréntesis en el inicio del mismo, indicando una parte que el copista del códice no pudo leer (este paréntesis no aparece, sin embargo, en el códice del Archivo del Hospital Tavera de Toledo); cabe la posibilidad de que Salazar sí leyese el documento entero y en esa parte que falta, que tampoco consta si era larga o corta, se hiciese referencia también a la madre de doña Guiomar.

92 Cantera Montenegro 1987: doc. 103.

93 Ibídem: doc. 333. También hace referencia al mismo Reglero de la Fuente 2014: 246, nota 20.
}

convento del dicho monesterio fuere la su mercet» y, como pago, entregaba al prior un lecho de ropa, pero añadía que, si éste no lo quisiera, se diese al hospital de dicho cenobio. Además donaba algunas propiedades en la Molina de Azo y en Valderrama para que se celebrasen aniversarios por él y por su mujer María Ruiz, ya fallecida, y para que rezasen por sus padres. A ello añadía la entrega de "un añal de oblada, oblación y candela» por él y su mujer en los altares de Santa María o de San Pedro de dicho monasterio, así como sendas libras de aceite para las lámparas del Crucifijo y de Santa María de Nájera.

Juan de Ruego, vecino de Nájera, también pidió en su testamento, redactado en 1400 , ser enterrado en el claustro, dejando también a la voluntad de los monjes el lugar concreto, pues solicita que sea "do por bien l'oviessen ${ }^{94}$; a ello unía la consiguiente donación de oblación y candela al altar de Santa María. Sin embargo, aquí nos encontramos con un hecho significativo: Juan de Ruego había hecho la víspera una primera disposición testamentaria ${ }^{95}$, y en ella había establecido ser enterrado en la Capilla de la Cruz, siendo el altar de la misma el beneficiario de la oblación y el lugar donde también deberían cantarse las misas de réquiem fijadas. Esta Capilla de la Cruz, como ya he dicho antes, estaba situada dentro de la iglesia conventual, y es en la que se encuentran enterrados los infantes; tenía capellanes propios designados por los monjes, aunque siempre hubo una relación muy difícil entre ambas partes, hasta que a mediados del siglo XVI se construyó una iglesia cerca del monasterio a la que se trasladaron la capilla y sus capellanes. ${ }^{96}$ Sin duda, este cambio en la disposición testamentaria sería uno de los muchos motivos de conflicto que jalonaron la historia de esta capilla, pues parece evidente que el cambio de lugar de entierro se debió a una presión más o menos fuerte de los monjes.

Sabemos de algunos litigios surgidos en otros momentos por las ofrendas entregadas con motivo de los funerales y misas que se decían en la iglesia destinataria del cuerpo, hasta que en 1496 ambas partes designaron como jueces árbitros al bachiller Diego Fernández de Arenzana de Yuso y al licenciado Pedro Martínez de la Canal de Tricio, quienes dictaron sentencia a favor de los capellanes ${ }^{97}$ : la ofrenda que correspondía al monasterio era la entregada en la primera misa celebrada solemnemente en el altar del Crucifijo de dicha capilla el día de la muerte; también establecieron que, si no fuese posible cantar la misa en dicho altar después de la vigilia de difuntos y se celebrase en el altar mayor de la iglesia monasterial, sería de esta misa de la que el abad y los monjes recibirían la media oblación.

No es éste el único pleito que surgió con motivo de los enterramientos en el monasterio. En 1498 el cura de la iglesia de San Nicolás de Somalo reclamaba a los cabezaleros del testamento de Juana de Valgañón, en concepto de canónica porción, la cuarta parte de las ofrendas realizadas porque la dicha Juana fue enterrada en el monasterio de Nájera, aunque había fallecido en Somalo. ${ }^{98}$ Pero este cura tuvo que aceptar la sentencia a favor del monasterio que

\footnotetext{
94 Cantera Montenegro 1987: doc. 417.

95 Ibídem: doc. 416.

96 Ibídem: I, 210-216.

97 Cantera Montenegro 2011: doc. 445.

98 Ibídem: doc. 493.
} 
dictó el vicario del obispo, Juan Martínez de Grañón, porque si, efectivamente, Juana había fallecido en esa localidad, la muerte ocurrió dentro del cortijo que pertenecía al monasterio, de modo que los que en él vivían eran parroquianos y vasallos del monasterio, y no de la parroquia de San Nicolás. ${ }^{99}$

Hay otras dos noticias de solicitud de entierro en el claustro najerense. Fernando Martínez de Santamaría ${ }^{100}$ lo hizo en su testamento redactado en 1429 , dejando a la voluntad de los monjes el lugar concreto del claustro donde ser enterrado; además encargó misas, vigilia y la entrega de oblación y candela, repartiendo estos encargos entre los monjes y los capellanes de la Cruz. Pocos años antes, Juan Pérez de Villar, tendero, y su mujer doña Sancha habían sido recibidos como familiares y enterrados a su muerte en el claustro, recibiendo los oficios religiosos correspondientes a esta condición jurídica. ${ }^{101}$

Parece lógico pensar que otras personas acogidas a esta misma fórmula jurídica a lo largo de la historia del cenobio recibieron también la contrapartida de ser enterrados en el recinto monástico; y ese sería el caso de Gonzalo Veilez, quien en 1124 entregaba su cuerpo y alma, junto con sus bienes, para la iluminación del altar de Santa María; o de Elvira Díaz, recibida como familiar y partícipe en todas las oraciones y bienes del monasterio y de la Orden de Cluny; o de Martín Juan de Hormilla y su mujer María López en 1444, quienes agradecían con esa entrega la ayuda que habían recibido del monasterio desde que eran jóvenes; y de María Sánchez de Valgañón, viuda, quien en 1509 pedía ser recibida como familiar del cenobio por parte de los monjes observantes. ${ }^{102}$

Las noticias de enterramientos en el monasterio se completan con la concesión de una sepultura que en 1459 hizo el prior mayor Gonzalo de Cabredo a favor de Diego Gutiérrez de Cañas, vecino de Nájera, por la ayuda prestada en las obras que en estos momentos se estaban realizando, "considerando las muchas et buenas obras et servicios et ayudas por infinitas et diversas veces». ${ }^{103}$ La localización de dicha sepultura se establecía precisamente en esa "obra nueva», que afectaba a la propia iglesia y a sus capillas; en concreto, el documento especifica que es «en la dicha obra nueva, saliendo de la puerta de la dicha iglesia mayor

\footnotetext{
99 Ibídem: doc. 565; año 1501.

100 Ibídem: doc. 116.

101 Ibídem: docs. 59 y 60. En el primer documento, de 1411, es Juan Pérez, ya viudo, quien donaba unas propiedades para ser recibido como familiar, al tiempo que pedía ser enterrado en el claustro. En el segundo, del mismo año, son los herederos de Sancha, que se señala falleció sin hacer testamento, los que entregan ciertos bienes al monasterio por haberla recibido como familiar y haberla enterrado en el claustro. Los familiares eran personas, a menudo ancianos o matrimonios sin hijos, que, por temor al futuro, se vinculaban a un monasterio o a otra institución religiosa por un pacto de ayuda: a cambio de entregar sus bienes, eran mantenidos materialmente (con alimento y vestido), participaban en los beneficios espirituales y oraciones de la comunidad y tenían derecho a ser sepultados en ese lugar. Sobre esta institución: Orlandis 1971 y 1954. Homet 1997: 101-118. Andrade Cernadas 2006-2012: 314 y 1997: 221 , nota 114 , señala que, aparte de este grupo de familiares, son pocas las personas que pidieron ser enterrados en los monasterios gallegos que estudia.

102 Cantera Montenegro 1987: docs. 39 (Gonzalo Veilez) y 377 (Elvira Díaz); y Cantera Montenegro 2011: docs. 145 (María López) y 694 (María Sánchez de Valgañón).

103 Cantera Montenegro 2011: doc. 188.
}

del dicho monasterio contra la plaza de la dicha cibdad, a la mano ezquerda», lo que parece referirse al atrio de la iglesia. La concesión se hace por juro de heredad, de forma que será el lugar de entierro del dicho Diego Gutiérrez «et de todos nuestros herederos et subcesores de vuestra generación et linage».

\section{El PANTEÓn DEL DuQue de NáJERA}

Este panteón es el único enterramiento que se encuentra dentro de la iglesia y está situado a mano izquierda del presbiterio. ${ }^{104} \mathrm{Su}$ establecimiento dentro de la iglesia responde, según el prof. Moya, a la transformación de hecho, que no de derecho, de la capilla mayor en panteón de los Manrique ${ }^{105}$, buscando también la cercanía al lugar más importante de la iglesia, el presbiterio, para obtener mayores beneficios en sufragio del alma. ${ }^{106}$

Dicho panteón fue realizado por el primer duque de Nájera, Pedro Manrique llamado el Fuerte, para recoger los restos de su primogénito Manrique, fallecido siendo muy joven, en 1493, momento en el que el Duque se entrometía con gran facilidad en la vida y rentas del monasterio. En 1506 fue enterrada allí su mujer, doña Guiomar de Castro, y finalmente el propio duque en $1515 .{ }^{107}$ En su testamento, el Duque disponía la entrega al cenobio de $20.000 \mathrm{mrs}$. de sus rentas en la ciudad para que se dijeran a perpetuidad dos Misas por su alma, la de su padre y la de su hijo Manrique. ${ }^{108}$ Posteriormente fueron enterrados otros miembros del linaje: en 1555 su nieto don Juan Esteban Manrique de Lara, III duque de Nájera y tesorero mayor de Vizcaya; en 1600 el cuarto duque, don Manrique de Lara, junto a su mujer doña María Girón y sus hijos Rodrigo y García, fallecidos siendo niños.

Señala Yepes cómo, siguiendo la antigua costumbre, en la iglesia de Santa María de Nájera no hay enterrada ninguna persona, «ni en el cuerpo de la iglesia ni en el crucero, salvo el primer duque de Nájera, don Pedro, por excelencia llamado el duque de Fortes, que después de 500 años en adelante que los reyes se sepultaron, se enterró en la capilla mayor al lado del Evangelio». ${ }^{109}$ Afirma el cronista que algunos fiscales del Consejo Supremo quisieron evitar que fuese enterrado en aquel lugar «pareciéndoles que estando los reyes a los pies, el duque no había de estar en tan supremo lugar»; pero finalmente se dejó allí, pues «ni parece que el duque tiene mejor lugar que los reyes, pues las coronas reales dondequiera que están hacen cabecera y nadie compite con ellos».

104 Santa María la Real de Nájera. Guía del visitante, Nájera, s.a.; Moya Valgañón 1986: 52. De Las Heras y Núñez 1992: I, 301, señala que este duque estaba enterrado en el testero de la iglesia «in cornu Evangelii».

105 Moya Valgañón 1989: 70.

106 Pavón y García de la Borbolla 2008: 229.

107 Salazar y Castro 1988: tomo II, libro VII, 143. Garrán 1909: 42-43; señala que el duque fue enterrado con el hábito de san Francisco.

108 Guinea y Lerena 2006: 268. Posteriormente, su hijo y sucesor del título ducal, Antonio Manrique, estableció que todos los presbíteros que celebraran misa en el altar mayor estarían obligados a decir un responso sobre la sepultura de su padre, obligación aceptada por el abad y los monjes (ibídem: 364).

109 Yepes 1960: 94. 
Realmente, en esta actitud contraria al entierro en ese lugar había un trasfondo mucho más profundo, aunque esa disculpa de la prelación que podía robar a los reyes aportaba un argumento de peso. La razón hay que buscarla en la conflictividad política de los años previos a la muerte del Duque, al encabezar éste el bando opuesto al gobierno de Fernando el Católico en Castilla ${ }^{110}$, así como en su directa intervención contra la reforma del cenobio najerense patrocinada por los Reyes Católicos, oponiéndose con todos los medios a su alcance a la implantación de la observancia vinculada a la Congregación de San Benito de Valladolid ${ }^{111}$, aprovechando para ello la propia división existente en la comunidad monástica. En esa intervención, la actuación del Duque estaba encaminada a evitar que un monasterio tan importante y enclavado en una región tan decisiva para su linaje acabase en manos hostiles o, al menos, desafectas al mismo; por ello apoyó al abad comendatario Fernando Marín frente a los observantes. De este modo, cuando en 1511 el citado Fernando Marín renunció a la abadía, aceptando la definitiva incorporación de Santa María de Nájera a la Congregación vallisoletana, la influencia del Duque sobre el monasterio se disipó totalmente; y los monjes observantes pudieron mostrar su disgusto por la anterior actuación del Duque oponiéndose a la manda recogida en su testamento, disponiendo ser enterrado en la iglesia, en el panteón donde yacía su hijo Manrique.

Salazar y Castro ${ }^{112}$ señala cómo los monjes pusieron como pretexto "que el sepulcro era más alto que el Altar Mayor, donde estava el Santísimo Sacramento, y los cuerpos Santos de los Mártires»; y sólo la conminación realizada por el propio rey en marzo y mayo de 1515 permitió que, por fin, se realizase el sepelio allí. A pesar de todo, provocaba «a los monjes tanta irritación contra los bultos, reja, escudos de armas, y adornos de aquel sepulcro» que presentaron pleito por este motivo en el Consejo «y alguna vez quitaron de hecho la tumba, bulto, y armas", alegando siempre que estaba a la misma altura que el altar y que, también, tenía lugar preferente sobre los 32 sepulcros reales.

En sentido semejante se manifiesta Constantino Garrán $^{113}$, quien afirma que algunos abades del siglo xVI quisieron privar a los duques de Nájera del honor de yacer en el presbiterio, "que no disfrutaban los reyes enterrados en el monasterio", motivo por el cual dos o tres veces se hicieron sacar los restos para colocarlos en un arco plateresco de la pared del lado del Evangelio, junto a la puerta de salida al claustro; ello dio lugar a una serie de «muy ruidosos pleitos» que se prolongaron varios años, hasta que se permitió restituir las cenizas al sarcófago del altar mayor, pero rebajándolo un poco para que quedase por debajo del altar y quitando la estatua yacente del Duque.

Estos pleitos que, por otra parte, hay que relacionar también con la situación política de Castilla y las rivalidades

110 Sobre esta actuación y los conflictos que por este motivo surgieron, Montero Tejada 1992.

111 Tema muy bien analizado por Diago Hernando 2012: 1253-1258 Sin olvidar los trabajos anteriores de este autor, en los que también aborda esta cuestión, aunque sin profundizar tanto en este personaje: Diago Hernando 1992a: 811-861 y 1992b: 667-697. Sobre estos conflictos entre el monasterio y el Duque por el intervencionismo contra derecho por parte de éste, ver Guinea y Lerena 2006: 186-200 y Cantera Montenegro 2011: docs. 322, 325, 526, 677, 678, 679, 682, 690 y 691.

112 Salazar y Castro 1988: 137-138.

113 Garrán 1909: 49. entre nobles, continuaron tras la muerte del primer Duque. Así lo podemos comprobar por el enfrentamiento que surgió en 1516 cuando los monjes observantes de Santa María de Nájera empezaron a realizar varias obras en el edificio por un doble motivo: acomodarlo a las exigencias de la Observancia vallisoletana y el mal estado de buena parte de la casa. La disputa en concreto se planteó en torno a la pared que daba a la calle del Canto, pues «dicha obra la quieren hacer por todo el monasterio hasta las peñas ${ }^{114}$; el concejo de Nájera, representado por Diego de Mijancas alegó ante el teniente del corregidor de la ciudad y teniente de justicia por el Duque, que los cimientos de dicha obra eran muy anchos, lo que daba a entender que la pared que iban a hacer era muy ancha y alta; y eso, según el citado representante del concejo, demostraba que con esa obra "harían abad y monasterio una casa fuerte contra las leyes del Reino, y por fatigar y molestar y maltratar a los vecinos de la ciudad por los pleitos que han tenido y tienen con algunos de ellos».

Durante todo este proceso, el entonces Duque de Nájera, Antonio Manrique de Lara, hijo de Pedro Manrique, mostró su recelo ante la actitud de los monjes, pues consideraba que efectivamente pretendían hacer un «edificio fuerte» para favorecer a quienes intentaban alborotar la ciudad contra él. ${ }^{115}$

A pesar de todo, finalmente se alcanzó un acuerdo el año siguiente ${ }^{116}$, de forma que el Duque y la ciudad consintieron que se hiciese la pared en cuestión, aceptando que, como alegaba el monasterio, era necesaria para guardar la observancia.

\section{CONCLUSIONES}

En la elección de sepultura influyeron muchos y variados factores, que son reflejo de la religiosidad medieval; y todos ellos están presentes en el caso de Santa María de Nájera. Su fundación va unida a la identificación del templo como panteón de los monarcas navarros; y aunque esta función desapareció con la incorporación del territorio riojano a Castilla en 1076, pervivió la vinculación sentimental al mismo como medio de justificar su dominio político sobre él.

También otras personas notables vinculadas al monasterio quisieron establecer en él su panteón funerario, destacando la familia Haro, protectora especial de este cenobio. En esta elección vemos la influencia del arraigo territorial de la familia en la región, así como la búsqueda de una comunidad religiosa que asegurase la continuidad de oración por los difuntos de la familia; y qué mejor opción que un cenobio cluniacense, con una numerosa comunidad que se comprometía a rezar por sus benefactores. Y así se produjo la fundación de las primeras capellanías; a cambio

114 AHN, Clero, leg. 2963 (1), de 5 y 6 de mayo de 1516.

115 En las preguntas que debían hacerse a los testigos en la encuesta que en 1516 se realizó sobre esta obra se hacía referencia a si la pared que se estaba haciendo era muy gruesa y alta "a manera de fortaleza e casa fuerte», de modo que los monjes harían casa fuerte en la que se podrían «alçar e encastillar», recordando también cómo en el monasterio se había acogido anteriormente a "malhechores e delincuentes», referencia clara a los enfrentamientos vividos poco antes.

116 AHN, Clero, leg. 2963 (1), de 8 de abril de 1517. 
de la entrega de determinados bienes, que aseguraban una renta suficiente, se garantizaba la celebración de aniversarios, Misas y otras oraciones. Pero junto al elemento religioso, otro de carácter familiar: el panteón aseguraba, además de las plegarias, mantener vivos los lazos del linaje más allá de la muerte y servir de referencia a las futuras generaciones.

Los enterramientos se realizaron en el pórtico a los pies de la iglesia, en el caso del panteón regio, ya que en aquel momento estaba prohibido el enterramiento en el interior de los templos. Y si los reyes no estaban enterrados en el interior, tampoco podían estarlo los demás cristianos, aunque fuesen nobles; por ello, se eligió el claustro contiguo a la iglesia para esta función cementerial, y precisamente la galería colindante al muro del templo sería el lugar por excelencia de entierro de los nobles, el Claustro de los Caballeros, en el cual se estableció una verdadera jerarquización de los espacios.

Junto a los Haro, otras familias nobiliarias, como los Salazar, Mendoza o Cabredo, se vincularon al monasterio najerense, quizás aprovechando el desapego que la familia Haro empezó a mostrar desde el siglo XIII hacia los monjes de Nájera, en favor de los franciscanos. Y ya en el siglo XIV consta el entierro de personas de toda procedencia social en el claustro, en la galería conocida como Claustro de los Confesores, aunque desde el primer momento hubo un grupo de fieles que gozaron del derecho de enterrarse en el recinto monástico, los familiares, personas que se integraban en la comunidad monástica, aunque no en la vida plenamente religiosa de la misma.

Y en el caso de Santa María de Nájera, el período medieval termina con la única excepción a la exclusión de entierros en el interior del templo, el Duque de Nájera; aunque esta excepcionalidad y las luchas políticas de principios del siglo XVI, tanto en el Reino de Castilla como en la ciudad de Nájera, provocaron un fuerte debate que obligó hasta en tres ocasiones a retirar el cuerpo del templo; si finalmente se aceptó su presencia fue con la condición de rebajar el arca funeraria y retirar la estatua yacente que se había hecho en el primer momento.

\section{BiBLIOGRAFÍA}

Álvarez-Coca González, M.ạ J. 1978. Escultura románica en piedra en La Rioja Alta. Logroño: Servicio de Cultura de la Excma. Diputación Provincial-Gonzalo de Berceo.

Andrade Cernadas, J. M. 1997. El monacato benedictino y la sociedad de la Galicia medieval (siglos X al XIII). La Coruña: Ediciós do Castro.

Andrade Cernadas, J. M. 2006. «Una aproximación a la historia de la vejez en la Galicia medieval: algunas fuentes y sus posibilidades de información». Semata 18: 238-241.

Andrade Cernadas, J. M. 2012. "Asilos monásticos: vejez y mundo cenobítico en el Noroeste hispánico entre los siglos IX al XI», en Mundos medievales: espacios, sociedades y poder. Homenaje al prof. José Ángel García de Cortázar: I, 311-324. Santander: Universidad de Cantabria.

Arco, R. del. 1954. Sepulcros de la Casa Real de Castilla. Madrid.

Argaiz, G. 1675. La Soledad laureada por San Benito y sus hijos en las iglesias de España, y Teatro monástico de la provincia Tarraconense. Madrid.

Aventin, M. 2001. "La familia ante la muerte: el culto a la memoria», en J. I. de la Iglesia Duarte (ed.), La familia en Ia Edad Media. XI Semana de Estudios Medievales. Nájera, del 31 de julio al 4 de agosto de 2000: 387-412. Logroño: IER.
Bango Torviso, I. 1992. «El espacio para enterramientos privilegiados en la arquitectura medieval española». Anuario del Departamento de Historia y Teoría del Arte IV: 93-132.

Baud, A. 1999. «La place des morts dans l'abbaye de Cluny. État de la question». Archéologie Médiévale XXIX: 99-114.

Boto Varela, G. 2012. «Aposentos de la memoria dinástica. Mudanza y estabilidad en los panteones regios leoneses (1157-1230)». Anuario de Estudios Medievales 42/2: 535-565.

Bougard, F., La Rocca, C. y Le Jan, R. (dirs.). 2005. Sauver son âme et se perpetuer. Transmission du patrimoine et mémorie au Haut Moyen Âge. Roma: École française de Rome. Cabe destacar especialmente los trabajos de L. To Figueras,

"Fondations monastiques et mémorie familiale en Catalogne ( $I \mathrm{X}^{\mathrm{e}}-\mathrm{XI}^{\mathrm{e}}$ siècle): 293-329; y Philippe Depreux, La dimension "publique" de certaines dispositions "privées": fondations pieuses et memoria en Francie occidentale aux IX et $x^{\mathrm{e}}$ siècles»: 331-378.

Cantera Montenegro, M. 1986. «Religiosidad en La Rioja bajomedieval a través de los testamentos (siglos XIII-XV)». Berceo 110-111: 111-154.

Cantera Montenegro, M. 1987. Santa María la Real de Nájera, siglos XI-XIV: 3 vols. Madrid: UCM.

Cantera Montenegro, M. 2001. «Santa María la Real de Nájera en la Edad Media», en J. I. de la Iglesia Duarte (coord.), I Semana de Estudios Medievales. Nájera, 1990: 207-229. Logroño: IER.

Cantera Montenegro, M. 2011. Colección documental de Santa María de Nájera, siglo XV. Regesta documental. Logroño: IER.

Cantera Montenegro, M. 2014. «Santa María la Real de Nájera, panteón de Reyes», en López Ojeda, E. (ed.), De la tierra al Cielo. Ubi sunt qui ante nos in hoc mundo fuere?: 261-296. Logroño: IER.

Carrero Santamaría, E. 2006. «El claustro funerario en el medievo o los requisitos de una arquitectura de uso cementerial». Liño: 12: 31-43.

Castañeda, V. 1929. El cronista fray Prudencio de Sandoval. Nuevas noticias biográficas. Madrid: Tipografía de Archivos.

De Las Heras y Núñez, M. a de los Á. 1992. «El claustro del monasterio de Santa María la Real de Nájera», en Comité Español de Historia del Arte (coord.), El arte español en épocas de transición: actas: I, 301-308. León: Universidad de León.

Dectot, X. 2006. "Las sepulturas de Sancho III y sus herederos», en I. G. Bango (dir.), La Edad de un Reyno, Las encrucijadas de la diócesis y la corona de Pamplona: 353-363. Pamplona: Fundación para la conservación del Patrimonio Histórico de Navarra.

Dectot, X. 2009. Les tombeaux des familles royales de la péninsule ibérique au Moyen Age. Turnhout: Brepols.

Diago Hernando, M. 1992a. «El intervencionismo nobiliario en los monasterios riojanos durante la Baja Edad Media. Encomiendas y usurpaciones». Hispania LII/3: 811-861.

Diago Hernando, M. 1992b. «La reforma de los monasterios riojanos en tiempo de los Reyes Católicos». Hispania Sacra 44: 667-697.

Diago Hernando, M. 1994. "Los Haro de Cameros en los siglos XIII y XIV. Análisis del proceso de su afianzamiento político en el ámbito regional», Anuario de Estudios Medievales 24: 775-806.

Diago Hernando, M. 2012. «Nobleza y reforma monástica en la Castilla tardomedieval. El papel de los Duques de Nájera en los monasterios riojanos", en Mundos medievales: espacios, sociedades y poder. Homenaje al prof. José Ángel García de Cortázar: II, 12471258. Santander: Universidad de Cantabria.

Español, F. 2003. "La polifuncionalidad de un espacio restringido», en J. Yarza Luaces y G. Boto Varela (coords.), Claustros románicos hispánicos: 11-29. León: Edilesa.

Estepa, C. 2002. «Dos testamentos femeninos en el siglo XIV: María de Haro y la reina María de Molina», en C. M. Reglero de la Fuente (coord.), Poder y sociedad en la Baja Edad Media hispánica. Estudios en homenaje al prof. Luis Vicente Díaz Martín: 375-392. Valladolid: Universidad de Valladolid.

Fortún Pérez de Ciriza, L. J. (dir.). 1991. Sedes reales de Navarra. Pamplona: Gobierno de Navarra.

Fortún Pérez de Ciriza, L. J. 2005. «Monjes y obispos: la Iglesia en el reinado de García Sánchez III el de Nájera», en J. I. de la Iglesia 
Duarte (coord.), XV Semana de Estudios Medievales. Nájera, García Sánchez III "el de Nájera». Un rey y un reino en la Europa del sigo XI: 191-252. Logroño: IER.

García Flores, A. 2005. «Espacios funerarios en los monasterios cistercienses de los reinos de Castilla y de León (siglos XII al XV)». Citeaux. Commentarii cistercienses 76: 199-229.

Garrán, C. 1909. Santa María la Real de Nájera. Monumento históricoartístico nacional. Apuntes para su primera visita arqueológicopopular. Soria: Imprenta de "Tierra Soriana».

González, J. 1969. El reino de Castilla en la época de Alfonso VIII. Madrid: Escuela de Estudios Medievales.

Guiance, A. 1998. Los discursos sobre la muerte en la Castilla medieval (siglos VII-XV). Valladolid: Junta de Castilla y León.

Guinea, D. y Lerena, T. 2006. Señores de la guerra, tiranos de sus vasaIlos. Los Duques de Nájera en La Rioja del siglo XVI. Logroño: Los Libros del Rayo.

Hergueta, D. 1969, 2ª ed. Historia de Haro. Madrid: Literoy. Selección y notas de Antonio Larrea.

Homet, R. 1997. Los viejos y la vejez en la Edad Media. Sociedad e imaginario. Rosario (Argentina): Pontificia Universidad Católica Argentina, Facultad de Derecho y Ciencias Sociales del Rosario, Instituto de Historia.

Íñiguez Almech, F. 1968. "Sobre tallas románicas del siglo XII». Príncipe de Viana 29: 181-236.

logna-Prat, D. 1996. "Des morts spécieux aux morts ordinaires: la pastorale funéraire clunisienne ( $\mathrm{II}^{\mathrm{e}}-\mathrm{XII}^{\mathrm{e}} \mathrm{s}$.)». Médiévales 31: 79-91

logna-Prat, D. 1998. "Les vivants et les morts», en D. logna-Prat, Ordenner et exclure. Cluny et la société chrétienne face à I'héresie, au judaïsme et à l'islam. 1000-1150: 219-252. París. Flammarion.

logna-Prat, D. 2002. "Los muertos en la contabilidad celestial de los monjes cluniacenes en torno al año 1000 », en L. K. Little y B. H. Rosenwein (eds.), La Edad Media a debate: 521-551. Madrid: Akal.

Martínez de Aguirre Aldaz, J. A. 2003. «La memoria de la piedra: sepultura en espacios monásticos hispanos (siglos XI y XII)», en Monasterios románicos y producción artística, 131-159. Aguilar de Campoo: Fundación Santa María la Real-C.E.R.

Mattoso, J. 1995. «O poder e a morte». Anuario de Estudios Medievales 25: $395-428$.

Mitre Fernández, E. 2002. "La muerte primera y las otras muertes. Un discurso para las postrimerías en el Occidente Medieval», en J. Aurell y J. Pavón (eds.), Ante la muerte. Actitudes, espacios y formas en la España medieval: 27-48. Pamplona: EUNSA.

Montero Tejada, R. 1992. «Ideología y parentesco: bases de la actuación política del primer Duque de Nájera a comienzos del siglo XVI». Espacio, Tiempo y Forma. Serie III. Historia Medieval V: 229-260.

Moya Valgañón, J. G. (dir.). 1986. Inventario artístico de Logroño y su provincia La Rioja. III. Morales-San Martín de Jubera. Madrid: Servicio Nacional de Información Artística, Arqueológica y Etnológica. Ministerio de Educación y Ciencia, Dirección General del Patrimonio Artístico y Cultural.

Moya Valgañón, J. G. 1989. "Así no». Anuario del Departamento de Historia y teoría del Arte 1: 69-78.
Orlandis, J. 1950. «Sobre la elección de sepultura en la España medieval». Anuario de Historia del Derecho Español 20: 5-49.

Orlandis, J. 1954. "Traditio corporis et animae (la familiaritas en las Iglesias y monasterios españoles en la alta Edad Media». Anuario de Historia del Derecho Español 24: 95-280.

Orlandis, J. 1971. «Los monasterios familiares en España durante la alta Edad Media», en J. Orlandis, Estudios sobre instituciones monásticas medievales: 125-164. Pamplona: Universidad de Navarra.

Ortego Rico, P. 2008. «El patrocinio religioso de los Mendoza: siglos XIV y XV». En la España Medieval 31: 275-308.

Pavón, J. y García de la Borbolla, J. 2008. Morir en la Edad Media. La muerte en la Navarra medieval. Valencia: Universitat de Valencia.

PP. Franciscanos. s.a. Santa María la Real de Nájera. Guía del visitante.

Reglero de la Fuente, C. M. 2008. Cluny en España. León: Centro de Estudios e Investigación» San Isidoro.

Reglero de la Fuente, C. M. 2014. Amigos exigentes, servidores infieles: La crisis de la Orden de Cluny en España (1270-1379). Madrid: Consejo Superior de Investigaciones Científicas.

Ruiz Maldonado, M. 1992. "Un sepulcro del arte 1200, en el monasterio de Santa María la Real de Nájera». Goya: revista de arte 226: 200-205.

Ruiz Maldonado, M. 1996. "Escultura funeraria del siglo XIII: los sepulcros de los López de Haro». Boletín del Museo e Instituto Camón Aznar 66: 91-170.

Salazar, J. de. 1987. Náxara ilustrada. Logroño: Patronato del Monasterio de Santa María la Real de Nájera (magnífica edición realizada por D. Salustiano Nalda Bretón de la obra escrita en 1629).

Salazar y Castro, L. de. 1988. Historia genealógica de la Casa de Lara. Acedo (Navarra): Wilsen editorial (edición facsímil).

Sandoval, P. de, 1614. Catálogo de los obispos, que ha tenido la Santa Iglesia de Pamplona; con un breve sumario de los Reyes que en tiempo de los obispos reynaron en Navarra. Pamplona.

Torija Rodríguez, E. 2014. "Las capillas funerarias reales de la catedral de Toledo. Elementos humanos y legitimadores", en Reyes y prelados: la creación artística en los reinos de León y Castilla (1050-1500), M.a D. Teijeira Pablos, M.a V. Herranz Ortega y M.a C. Cosmen (coords.): 295-307. Madrid: Sílex.

Valdez del Álamo, E. 2000. «Lament for a lost Queen: the sarcophagus of Doña Blanca in Nájera», en E. Valdez del Álamo y C. Perdergast (eds.), Memory and the Medieval Tomb: 43-79. Aldershot: Ashgate.

Valdez del Álamo, E. 2001. "Lauda sepulcral de Doña Blanca», en I. Bango Torviso (dir.), Maravillas de la España medieval: 138-139. Valladolid: Junta de Castilla y León-Caja España, vol. II.

Valdez del Álamo, E. 2006. "Los reyes hispanos socios de Cluny», en I. G. Bango (dir.), La Edad de un Reyno, Las encrucijadas de la diócesis y la corona de Pamplona: 797-806. Pamplona: Fundación para la conservación del Patrimonio Histórico de Navarra.

Yarza Luaces, J. 1988. "La Capilla funeraria hispana en torno a 1400», en M. Núñez y E. Portela (coords.), La idea y el sentimiento de la muerte en la Historia y en el Arte de la Edad Media: 67-91. Santiago de Compostela: Universidad de Santiago de Compostela.

Yepes, A. de, 1960. Coronica general de la Orden de San Benito, patriarca de religiosos. Madrid: Biblioteca de Autores Españoles (edición facsímil de la edición de 1609-1621). 